\title{
Overcoming Adverse Selection: How Public Intervention Can Restore Market Functioning
}

\author{
Jean Tirole ${ }^{\dagger}$
}

January 21, 2011

\begin{abstract}
The paper provides a first analysis of market jumpstarting and its two-way interaction between mechanism design and participation constraints. The government optimally overpays for the legacy assets and cleans up the market of its weakest assets, through a mixture of buybacks and equity injections, and leaves the firms with the strongest legacy assets to the market. The government reduces adverse selection enough to let the market rebound, but not too much, so as to limit the cost of intervention. The existence of a market imposes no welfare cost.
\end{abstract}

Keywords: market freeze; market rebound; asset repurchases; recapitalization; mechanism design; mechanism-dependent participation constraint.

JEL numbers: D82, D86, G01, H81.

\section{Introduction}

Motivation. As illustrated by the recent crisis, market freezes are one of the most damaging market failures. In reaction, governments often attempt to "liquify" or "rejuvenate" the asset markets; such interventions take the form either of asset buybacks (as was envisioned in the

\footnotetext{
†Toulouse School of Economics. TSE, Université de Toulouse, Manufacture des Tabacs, 21 allées de Brienne, Fr - 31000 Toulouse. E-mail: jean.tirole@tse-fr.eu. I'm grateful to participants at seminars at Harvard Law School, LSE, MIT, Stanford and Tel Aviv University, and at conferences at Boston University, the ECB and the Fédération Bancaire Française, Elena Carletti, Florian Heider, Sergei Kovbasyuk, Thomas Mariotti, Patrick Rey, three anonymous referees, and especially Gabriel Carroll and Jean-Charles Rochet for very helpful comments. The research leading to these results has received funding from the European Research Council under the European Community's Seventh Framework Programme (FP7/2007-2013) Grant Agreement no.249429.
} 
TARP I and II programs) or of a host of policies, such as central banks' acceptance of toxic assets as collateral, loan guarantees, or equity injections, that leave the assets on the balance sheet of the financial institution. Participation in these schemes is by and large voluntary. ${ }^{1}$

This paper offers a first formal analysis of market rejuvenation. It traces market freezes to adverse selection and investigates the consequences of this assumption for policy-making. ${ }^{2}$ It builds on the idea that institutions participate in the government scheme only if what they receive in it exceeds what they obtain in the marketplace, and that the market outcome depends on who participates in the scheme. Put differently, reservation utilities in the mechanism designed by the government depend on the mechanism itself.

The paper features firms which do not have enough cash to finance a new project, but hold legacy assets whose value is unknown to a competitive financial market. Agency costs in the new project imply that the seller is credit-constrained; accordingly, she must sell a share or the totality of her legacy asset. Potential buyers however are imperfectly informed about the quality of this legacy asset.

Small adverse news in the market for legacy assets may generate a discontinuity in the volume of trade and prevent firms from accessing the funds they need to finance their project. The government may then intervene by buying or taking a stake in the assets. The government, which maximizes a mixture of firm and taxpayer welfares and is therefore hesitant to leave large rents to firms, moves first and proposes a mechanism. After firms have chosen to participate or stay out, the financial market offers financing to firms that have turned down the government's offer. Thus, and in contrast with standard mechanism design, we allow non-participating sellers to benefit from the potential market rebound induced by the government's intervention.

A stripped down version. Let $I$ and $S$ denote the new project's investment cost and net

\footnotetext{
${ }^{1}$ Presumably because of possible allegations of expropriation and lawsuits. Even the one intervention with a taste of compulsion, the October 13, 2008 insistence by Secretary Paulson that 9 top banks sell shares to the government, was not fully compulsory if only because under U.S. law the government cannot force public capital into a private institution. Instead, Paulson relied on the (credible?) threat that a bank would be ineligible for support in case of a crisis if it refused to be injected with capital. The banks furthermore had a fair amount of leeway in reimbursing the corresponding loans. The contemporaneous rescue plan in the UK was taken up mostly by the bad apples, with stronger banks (like Barclays) refinancing themselves in the marketplace. Similarly, the Japanese bailout experience in the 1990s was characterized by a substantial holdout problem (Takeo Hoshi and Anil Kashyap 2010).

${ }^{2}$ Adverse selection is only one of several hypotheses for why markets froze in 2008. See Section V.
} 
return. Suppose a complete lack of pledgeability: the entire return in case of investment accrues to the firm. The legacy asset returns 1 with probability $\theta$. Furthermore, the firm knows $\theta$ but outsiders believe that it is $U[\gamma, 1]$ with $\gamma \geq 0$. At a price $p<I$, there will be no gains from trade and therefore no trade. At $p \geq I$, sellers with $\theta \leq p+S=\theta^{*}$ will sell. Assuming buyers compete to zero profit, this means that the price is equal to the truncated mean $p=E[\theta \mid \theta \leq$ $p+S]=m^{-}(p+S)=\frac{1}{2}(\gamma+p+S)$, or that $p=\gamma+S .^{3}$

So we have two possibilities: (1) if $\gamma+S<I$, there is no trade; (2) if $\gamma+S \geq I$, then all firms with assets $\theta \leq \gamma+2 S$ trade at a price $p=\gamma+S$. If we assume that $S<I$ and $\gamma=0$, we have complete market failure. An increase in $\gamma$, however, can "re-start" the market. For example, if types $\theta \leq I-S$ are removed from the market, we re-introduce trade and allow types between $I-S$ and $I+S$ to trade.

The private market interacts with a government intervention to buy assets. Suppose the government posts a price $p \geq I$. If there were no private market, all types with $\theta \leq p+S$ would sell to the government. If there is a post-intervention market, however, then once types with $\theta \leq p+S$ have sold, additional types trade on the private market at a strictly higher price - and anticipating this, low types would hold out from the intervention. Instead, the equilibrium has the feature that the government and private market prices are equated at $p$, that types between $p-S$ and $p+S=\theta^{*}$ sell in the private market, and types $\theta<p-S$ sell to the government. The government loses money, the private buyers break even.

Finally, suppose that the government faces a shadow cost of public funds $\lambda$, and therefore trades off total surplus from inducing trade and taxpayer losses. If the market does not freeze and is characterized by cutoff $\theta^{*}$, the government does not intervene if the increase in the cost of inframarginal rents exceeds the marginal efficiency gain: $\lambda F\left(\theta^{*}\right) \geq(1+\lambda) f\left(\theta^{*}\right) S$ (where $F$ and $f$, the c.d.f. and density, are here uniform), or $\lambda \geq 1$. However, if the market freezes ( $\gamma$ falls below $I-S$ ), the government optimally allows the market to rebound to its minimum volume of activity provided that $(1+\lambda) S \geq \lambda(I+S-\gamma) / 2$, which, for any given $\lambda$, is satisfied provided that $I-\gamma$ is not too much above $S$.

General model. The actual model is richer in a couple of ways. First, the distribution of

\footnotetext{
${ }^{3}$ I assume that $\theta^{*}<1$, or equivalently that $\gamma+2 S<1$ to knock out a boundary case.
} 
types need not be uniform. Second, some of the proceeds of the new project are pledgeable, so the government and private investors are not limited to posting a price - they can offer to take a stake in the new project; relatedly, pledgeability allows asset buybacks to re-start the credit market for new projects. Third, the government and buyers can take a partial stake in the legacy asset. We therefore need to think in terms of incentive compatible contracts and the utilities they generate. Starting from an initial population of types $\Theta$, let $U_{g}(\theta)$ and $C_{g}(\theta)$ denote type $\theta$ 's rent and contract allocation in the government's mechanism, and $U_{m}\left(\theta ; \Theta_{m}\right)$ and $C_{m}\left(\theta ; \Theta_{m}\right)$ her rent and contract allocation in the marketplace for subset $\Theta_{m} \subseteq \Theta$ of holdouts. In an endogenous participation constraint equilibrium for given rent profile $U_{g}(\cdot)$, the sets of types who join the government intervention, $\Theta_{g}$, and of those who opt for the market, $\Theta_{m}$, are disjoint and satisfy $\Theta_{g} \cup \Theta_{m} \equiv \Theta$. Furthermore

$$
U_{g}(\theta)>U_{m}\left(\theta ; \Theta_{m}\right) \Longrightarrow \theta \in \Theta_{g}
$$

and

$$
U_{m}\left(\theta ; \Theta_{m}\right)>U_{g}(\theta) \Longrightarrow \theta \in \Theta_{m}
$$

The government's task is then to find an incentive compatible mechanism $C_{g}(\cdot)$ and resulting rent function $U_{g}(\cdot)$ so as to maximize welfare subject to the constraint that the collated overall rent $U(\theta)$ and allocation $C(\theta)$ be the outcome of a (if possible unique) endogenous participation constraint equilibrium for rent profile $U_{g}(\cdot)$.

Main insights. The optimal intervention is characterized by:

1) Pecking order. The government optimally buys back the weakest assets (thus cleaning up the balance sheet of their owner), and then finances firms with assets of intermediate quality while leaving these assets on the firms' balance sheet. The government leaves the strongest legacy assets to the market.

2) Non-comprehensive intervention and market rebound. Authorities cannot substitute fully for the market, even though they have no comparative disadvantage in acquiring assets or shares thereof. At the optimal policy, unless the government sets such a high price that it buys all legacy assets (which is always too costly and suboptimal), the market rebounds. The government must therefore account for the fact that by cleaning up the market of its weakest assets, it 
creates its own competition: Anticipating the ensuing market rebound, firms hold out unless the government is generous enough. The government optimally reduces adverse selection enough to let the market rebound, but not too much, so as to limit the cost of intervention.

3) Costly intervention. While it is correct that firms in need of cash are willing to sell assets at prices below their fundamental value, the market already reflects this willingness to engage in fire sales. Rejuvenating a market is necessarily expensive. Actually, we show that the government loses money on each financed type. ${ }^{4}$

4) No desire to shut down the market. Another key result is that the voluntary participation constraint can be made costless through a proper choice of policy. That is, as long as the law forces the government not to expropriate property (firms receive at least as much as they would obtain by keeping their legacy assets), there is no gain for the government from having the power to shut down the market; the presence of a market, though, deeply impacts the pattern of government intervention.

5) When is intervention desirable? That adverse selection creates a market failure need not vindicate a public intervention. Even in the absence of ex-ante moral hazard, the budgetary cost makes the government reluctant to try to correct the market failure. However, the accrual of (even small) bad news about asset quality may freeze the market and lead the government to switch from laissez-faire to intervention.

6) Intervention creates moral hazard. The prospect of a government intervention always reduces the incentives to create high-quality assets.

The paper is organized as follows. Section I. sets up the model. Section II. analyzes the case of "buybacks only", in which the seller keeps no skin in the game, which corresponds to situations in which only the owner can access the revenue on the legacy asset. ${ }^{5}$ Besides being of

\footnotetext{
${ }^{4} \mathrm{~A}$ premise of the US Treasury plans for asset repurchases was that they would not be very costly to US taxpayers; authorities as well as a number of observers argued that as financial institutions were desperate to raise cash, assets were "undervalued". Governments, the argument went, would intervene where current market values most differed from the fundamentals, and so governments' involvement in asset repurchases could even turn a profit. Conversely, other observers (e.g., Bebchuk, Buiter, Krugman and Sachs) expressed concern about the plans' potential cost to the taxpayer. This paper articulates their concerns and argues that in an adverse selection world, the optimistic view ignores the fact that if the Treasury's plan has been successful and had purged the market from its most toxic assets, the resulting market rejuvenation would have had the effect of boosting asset prices, and thereby of making asset owners reluctant to depart from their assets.

${ }^{5}$ This situation covers for example government guarantees to revive securitization markets.
} 
independent interest, this case illustrates key insights in a straightforward manner and unveils an analogy with Coase's durable good monopolist. The optimal policy for a government is either laissez-faire or intervention. As for Coase's durable good monopolist, the government creates its own competition. By cleaning up the market from its more toxic pieces, it revives the market and makes it attractive for the sellers not to join the government's initiative. Yet, and unlike what would be suggested by Coasian profit evasion, the existence of a later market imposes no welfare cost. We also extend the model to allow for an ex-ante choice of asset quality; unsurprisingly the prospect of government intervention creates moral hazard.

All insights carry over to general mechanisms, in which the seller can retain some stake in the legacy asset. Section III., which is of independent interest relative to the Rothschild-Stiglitz literature, studies laissez-faire. We show that the "constrained efficient allocation", namely the one that yields the highest social surplus subject to seller incentive compatibility and buyer break-even constraint, is an equilibrium of the market game. Furthermore this is the only equilibrium that survives a "robust choice" refinement. Section IV. looks at optimal government intervention. Because the possibility of requiring some "skin in the game" somewhat alleviates adverse selection, the optimal intervention is more extensive than under buybacks only. Furthermore, the government cleans up the market, first through outright purchases of the weakest assets and then through some recapitalization, and leaves the firms with the strongest legacy assets to the market. Finally, at the optimum the government again loses money on all types who join the scheme. Section V. discusses modeling choice variants and Section VI. concludes with a few interesting research topics in this area. Omitted proofs can be found in the web appendix.

\section{Relationship to the literature}

The paper most obviously builds on the literature on market breakdowns initiated by George Akerlof (1970); see e.g., Igal Hendel and Alessandro Lizzeri (1999, 2002) for dynamic extensions and Patrick Bolton, Tano Santos, and Jose Scheinkman (2009), Florian Heider, Marie Hoerova, and Cornelia Holthausen (2010), Pablo Kurlat (2010), and Frédéric Malherbe (2011) for recent applications to the financial crisis. Relatedly, the literature initiated by Michael Rothschild and Joseph Stiglitz (1976) (e.g., Martin Hellwig 1987) has looked at the existence and characterization of equilibria in screening models with divisibility and exclusivity. Andrea At- 
tar, Thomas Mariotti, and François Salanié (2009) show that the Akerlof outcome obtains under divisibility provided that relationships be non-exclusive. Eric S. Maskin and Jean Tirole (1992) characterize equilibria of the signaling (informed principal) version of Rothschild-Stiglitz models. $^{6}$ The entire literature however builds on the assumption of exogenous participation constraints. This assumption is inappropriate when the market responds to the mechanism built by the designer.

The paper is also related to the literature on competitive price discrimination (e.g., Bruno Biais, David Martimort, and Jean-Charles Rochet 2000, Rochet and Lars Stole 2002, Biais and Mariotti 2005, and Mark Armstrong and John Vickers 2001, 2010) in that participation constraints are endogenous to the equilibrium. In that literature, though, contract offers are simultaneous and so the reservation utilities are not affected by the mechanism chosen by the designer, who therefore takes them as exogenous.

Augustin Landier and Kenichi Ueda (2009) and Thomas Philippon and Philipp Schnabl (2009), and Philippe Aghion, Patrick Bolton, and Steven Fries (1999) analyze the trade-offs involved in recapitalizing the banking sector under adverse selection and moral hazard, respectively. ${ }^{7}$ They consider compulsory schemes, in that banks are not allowed to refinance themselves in the marketplace if they don't participate in the government's mechanism. Again, the issue of mechanism-dependent participation constraint does not arise. Neither does it arise in the work on optimal securitization design (e.g., Aghion, Bolton and Tirole 2004, Antoine Faure-Grimaud and Denis Gromb 2004).

The theme that regulation and markets feed back on each other has been developed by Faure-Grimaud in rather different contexts, in which, in contrast with this paper, regulation is compulsory: In his 2002 contribution, the regulator uses stock information provided by the financial market in order to improve the regulatory scheme, which in turn affects stock price determination; his 1997 piece examines the regulation of predatory firms.

With the literature on auctions with externalities (starting with Michael Katz and Carl Shapiro 1986 and Philippe Jéhiel and Benny Moldovanu 1996), the paper shares the property

\footnotetext{
${ }^{6}$ This short list of references obviously does not do justice to this extremely rich literature.

${ }^{7}$ Enrico Minelli and Salvatore Modica (2009) looks at optimal subsidies to lending by a monopolistic bank facing adverse selection in the loan market.
} 
that reservation utilities are mechanism dependent; that literature mostly does not emphasize informational externalities. The literature on auctions with resale (e.g., Charles Zhoucheng Zheng 2002, Philip Haile 2003) by contrast builds on the idea that a market will emerge between winners and losers of the auction. There is of course no ex post transfer of contracts with the principal in our model. In Giacomo Calzolari and Alessandro Pavan (2006), a consumer with unknown type faces a sequence of two suppliers with possibly related (e.g. complementary) products. The first supplier chooses not only a non-linear tariff, but also how much information to disclose to the second supplier; this information allows the second supplier to better price discriminate, but may hurt the buyer, making the first offering less attractive. The first supplier commits to a disclosure policy and charges the second supplier for the information. Calzolari and Pavan obtain conditions under which full or partial privacy are optimal. In Lizzeri (1999)'s model of certification, Wolfgang Pesendorfer (1995)'s model of fashion and Roland Bénabou and Tirole (2006)'s model of prosocial behavior, a simple incentive scheme (a price) determines not only the incentive to participate, but also the agent's payoff in the absence of participation through sorting and subsequent reputation. ${ }^{8}$ As in this paper, acceptance decisions generate informational externalities.

The most closely related research is an independent contribution by Philippon and Vasiliki Skreta (2010), who also look at how a subsequent market may constrain the design of bailouts. In contrast with this paper, they assume that only total return (legacy + project) is observable. This rules out buybacks or any scheme contingent on the legacy asset's payoff, and results in a different characterization of the optimal intervention. Allowing for a continuum of payoff realizations and assuming that payments to investors (market, government) are monotonic in total return, they show that it is strictly optimal to intervene with debt contracts; in particular debt guarantees dominate equity injections, while my binary outcome model does not distinguish among interventions leaving the asset on the balance sheet.

Finally, and also closely related, the large literature on the durable good monopolist, initiated by Ronald H. Coase (1972), shares the insight that the principal may create his own competition. We will later explain why, in contrast with Coasian profit evasion, welfare is not reduced by the

\footnotetext{
${ }^{8}$ Reputations derived from accepting the scheme and turning it down are both relevant.
} 
prospect of a later market.

\section{Model}

\section{a) Preferences and technology}

All parties are risk-neutral. A "firm" or "seller" is cashless and protected by limited liability, owns a legacy asset, and has a new project to finance (or an old project in need of refinancing). Because she has no cash, she must rely on the sale of her legacy asset or on the issuance of securities backed by this asset in order to finance the project. Yet, as in Stewart C. Myers and Nicholas S. Majluf (1984), ${ }^{9}$ this process is marred with adverse selection.

Legacy asset. A legacy asset pays off $R_{0}$ in case of success and 0 in case of failure. The probability of success, $\theta$, is known only to the seller, and is distributed according to some continuous cumulative distribution function $F(\theta)$ on $[0,1]$, with density $f(\theta)$. The distribution function $F(\theta)$ is assumed to be log-concave (its hazard rate $f(\theta) / F(\theta)$ is decreasing).

The "legacy asset" can alternatively be interpreted as a nominal claim $R_{0}$ on a counterparty. The parameter $\theta$ then reflects both the probability that the counterparty will be able to pay back and the fraction of the claim that can be recouped in bankruptcy.

New project. The new project is the same for all seller types. It involves an investment cost $I$ and yields no income if the seller misbehaves, in which case she obtains a high private benefit $B$, but the new project then has negative social value: $B<I$. It yields sure verifiable income $R_{1}$ and (nonpledgeable) private benefit $b, 0<b<B$, if the entrepreneur behaves. The existence of credit rationing will hinge only on the property that $B>0$. Assuming further that $b>0$ will give scope for optimal interventions that do not necessarily imply universal financing; assuming $B>b$ will imply that some buybacks (in which the seller keeps no skin in the game) are optimal even when the optimal mechanism is used. These properties do not complicate the analysis. Let

$$
S \equiv R_{1}+b-I
$$

denote the corresponding surplus.

\footnotetext{
${ }^{9}$ Unlike in Myers-Majluf and Philippon-Skreta's "fungibility case", though, separate claims can be written on the legacy asset and on the new project. Section V. briefly discusses the fungibility case.
} 
Assumption 1. (positive NPV): $S>0$.

The next assumption ensures that the seller cannot finance the project on a stand-alone basis and therefore must sell a stake in, or the full legacy asset in order to undertake the new project. In order to prevent the seller from misbehaving, the latter must have a financial stake $B-b$ in the project's success. ${ }^{10}$ The "pledgeable income" is therefore $R_{1}-(B-b)$.

Assumption 2. (scope for credit rationing): In the absence of legacy asset, the seller would be unable to secure financing:

$$
R_{1}-(B-b)<I \Longleftrightarrow S-B<0 \text {. }
$$

The third assumption ensures that, under symmetric information, high- $\theta$ types would be able to obtain financing:

Assumption 3. (collateralization may enable financing): Collateral is valuable for the best types ( $\theta$ close to 1$)$ under symmetric information: $R_{0}+[S-B]>0$.

Government. The government faces a shadow cost $\lambda$ of public funds at the time of the bailout and maximizes expected gross social surplus

$$
W=E[U(\theta)]+\pi-(1+\lambda) D
$$

where $D$ is the deficit, $U(\theta)$ the seller's gross utility, and $\pi$ the buyers' expected profit. Letting $x(\theta)=1$ if the project is implemented and $=0$ otherwise, and provided that the market breaks even $(\pi=0)$, which it will do in equilibrium, social welfare satisfies: ${ }^{11}$

$$
W=(1+\lambda) E\left[\theta R_{0}+x(\theta) S\right]-\lambda E[U(\theta)]
$$

\section{b) Timing}

The timing is summarized in Figure 1. Let us start with the case of laissez-faire, which amounts to omitting stages 2 and 3 (in bold in Figure 1). At stage 1, the seller privately learns

\footnotetext{
${ }^{10} \mathrm{As}$ is standard, in order to avoid "openness problems" (and the concomitant need for approximate implementation), we will assume throughout the paper that, when indifferent, the seller behaves in the buyer's best interest.

${ }^{11}$ Note that $E[U(\theta)]+\pi-D=E\left[\theta R_{0}+x(\theta) S\right]$. Eliminating $D$ yields $W=(1+\lambda) E\left[\theta R_{0}+x(\theta) S\right]-$ $\lambda[E[U(\theta)]+\pi]$. Finally, buyers break even $(\pi=0)$ in equilibrium.

Note also that under symmetric information about $\theta$ and in the absence of financing $\left(\theta R_{0}<B-S\right)$, the government would want to enable financing by bringing subsidy $B-S-\theta R_{0}$ if and only if $(1+\lambda) S \geq \lambda\left(B-\theta R_{0}\right)$.
} 
$\theta$, the probability of success of her legacy asset. At stage 4, competitive buyers make contract offers (buyer $i$ offers a menu of contracts, $C_{i}(\theta)$ for each $\theta$ : see below). Then at stage 5 , the seller chooses one or none of the offers. Payoffs are realized at stage 6.

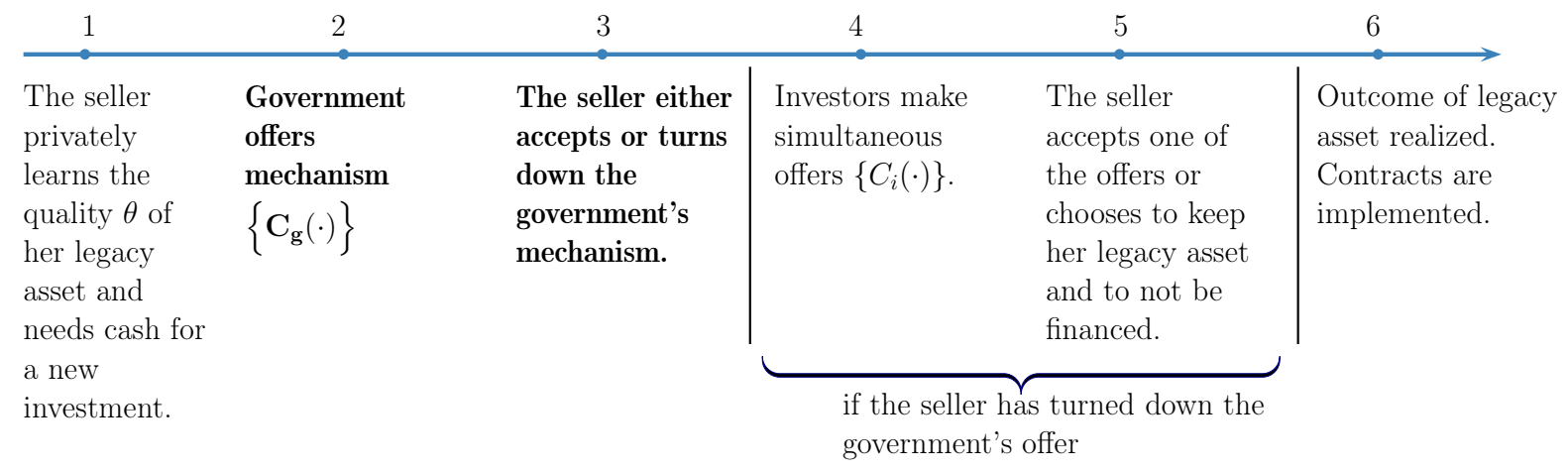

Figure 1: timing

Under government intervention, the government designs a contract $\left\{C_{g}(\cdot)\right\}$ at stage 2, i.e., before the market clears. At stage 3, the seller either accepts the offer or receives offers from the market at stage 4 .

c) Reservation utilities

In the absence of a contract with a buyer or the government, a seller obtains her "autarky outcome". Let $U_{0}(\theta)$ denote the autarky utility. We focus on the case of a fleeting opportunity/urgent need: The new investment opportunity requires an immediate (before stage 6) action. Then ${ }^{12}$

$$
U_{0}(\theta)=\theta R_{0}
$$

\section{d) Contracts}

A contract or mechanism (proposed by a buyer/financier $i=1,2, \cdots, \infty$ or by the government, $i=g$ ) maps a type announcement into an investment decision and contingent transfers. Without loss of generality, the seller receives nothing when the new project is financed and

\footnotetext{
${ }^{12}$ The analysis fully extends to the case of a less urgent need/Hirshleifer destruction-of-insurance effect case, in which the investment opportunity is still available at stage 6 , but will have to be financed under common knowledge about the realization of the legacy asset. Because refinancing at stage 6 occurs only when the legacy asset pays off and the seller receives the entire surplus under a competitive capital market, $U_{0}(\theta)=\theta\left(R_{0}+S\right)$. More generally, the need may be more or less urgent (for example due to discounting or to the possibility that a rival might step in and preempt before stage 6) and so $U_{0}(\theta)=\theta\left[R_{0}+\delta S\right]$, where $0 \leq \delta \leq 1$. Fleeting opportunities simplify the formulas and exposition, and so we focus on them for expositional purposes.
} 
delivers no revenue. ${ }^{13}$ A contract,

$$
\widehat{\theta} \longrightarrow C_{i}(\widehat{\theta}) \equiv\left\{z_{i}(\widehat{\theta}), y_{i}(\widehat{\theta}), x_{i}(\widehat{\theta})\right\}
$$

thus consists of

$\checkmark$ a type-contingent fixed (independent of legacy project outcome) reward for the seller: $z_{i}(\widehat{\theta}) \geq$ 0

$\checkmark$ a type-contingent reward that is conditioned on the success of the legacy project (skin in the game): $y_{i}(\widehat{\theta}) \geq 0^{14}$

$\checkmark$ a type-contingent investment decision for the new project: $x_{i}(\widehat{\theta}) \in\{0,1\}$.

Note also that we focus on deterministic contracts $\left(x_{i}(\widehat{\theta})=0\right.$ or 1$)$. Besides being realistic, I conjecture that this assumption actually involves no loss of generality.

As usual, one can restrict attention to truthful mechanisms $(\widehat{\theta}=\theta)$. We let $U_{i}(\theta)$ and $\pi_{i}(\theta)$ denote the seller's utility and the buyer's profit under $i$ 's mechanism when the seller has type $\theta$.

e) Incentive compatibility

Definition 1. A mechanism $\{z(\cdot), y(\cdot), x(\cdot)\}$ is trivial if $x(\theta)=0$ for all $\theta$; it is non-trivial otherwise.

Note that all types receive utility at least $B$ if the mechanism is non-trivial: Any type can then pretend to be a type that receives financing, shirk and receive $B$.

Definition 2. A non-trivial mechanism $\{z(\cdot), y(\cdot), x(\cdot)\}$ satisfies incentive compatibility (IC) if

(i) $U(\theta) \equiv \mathcal{U}(\theta, \theta) \geq \mathcal{U}(\theta, \widehat{\theta})$ for all $(\theta, \widehat{\theta})$ where $\mathcal{U}(\theta, \widehat{\theta}) \equiv \max _{\{\hat{\theta}\}}\{b x(\widehat{\theta})+z(\widehat{\theta})+\theta y(\widehat{\theta})\} \quad$ and $\mathcal{U}(\theta, \theta) \geq B$

(ii) $U(\theta) \geq U_{0}(\theta)$ for all $\theta$.

\footnotetext{
${ }^{13}$ In the notation below, let $\widetilde{z}_{i}$ and $\widetilde{y}_{i}$ denote the fixed and variable rewards when for some type $\theta, x_{i}(\theta)=1$ and the new project fails. These variables are irrelevant if the seller is induced to behave; so assume that she misbehaves. The seller could alternatively set these rewards to 0 and let $z_{i} \equiv \widetilde{z}_{i}+B-b$ and $y_{i}=\widetilde{y}_{i}$. This alternative contract induces effort in the new project and delivers the same utility to the seller (for this particular type as well as any other type) and a higher profit to buyer $i$.

${ }^{14}$ In principle, $y_{i}(\theta)$ could conceivably be negative without violating limited liability if $z_{i}(\theta)>0$. But there is obviously no loss of generality involved in assuming that the contingent reward is non-negative.
} 
Note that (IC) requires that $y(\cdot)$ be non-decreasing; and that the gross rent function $U(\cdot)$ be a continuous, increasing and convex function. For conciseness we include individual rationality into the definition of incentive compatibility.

f) Definition of equilibrium

Suppose that in equilibrium types $\theta \in \Theta_{g}$ accept the government's offers at stage 3 . The complementary subset of types $\Theta_{m}$ (such that $\Theta=[0,1]=\Theta_{g} \cup \Theta_{m}$ ) remain in the marketplace at stage 4. Let $F_{m}(\cdot)$ denote the cumulative distribution conditional on $\theta \in \Theta_{m} \cdot{ }^{15}$ We will let $U_{m}(\theta)$ denote type $\theta$ (in $[0,1]$ )'s utility in the marketplace. We let $E[\cdot]$ denote expectations relative to the prior distribution $F$, and $E_{\Theta_{m}}[\cdot]$ those relative to subset $\Theta_{m}$.

Our equilibrium notion is the standard concept of perfect Bayesian equilibrium:

Definition 3. (market equilibrium for a subset of types $\Theta_{m}$ ): A market equilibrium for distribution $F_{m}(\theta)$ on $\Theta_{m}$ is a set of IC offers by buyers $\left\{z_{i}(\widehat{\theta}), y_{i}(\widehat{\theta}), x_{i}(\widehat{\theta})\right\}_{i=1, \ldots, \infty}$ and an ensuing deterministic allocation of seller types $\left\{\Theta_{i}\right\}_{i=0,1, \cdots, \infty}$ such that:

(i) sellers optimally allocate among buyers or select autarky:

$$
\forall \theta \in \Theta_{m}: \quad U_{m}(\theta)=\max \left\{\sup _{i \in\{1, \cdots, \infty\}} U_{i}(\theta), U_{0}(\theta)\right\} .
$$

$\Theta_{i}$ denotes buyer i's resulting clientele, i.e., the set of all types attracted by buyer i's offer (support of $\Theta_{i} \subseteq\left\{\theta \mid i \in \arg \max _{\{j=0,1, \cdots, \infty\}}\left\{U_{j}(\theta)\right\}\right\}$ ) and $\Theta_{0}$ the set of buyers who do not contract with a buyer: $\Theta_{m}=\underset{\{0, \cdots, \infty\}}{\cup} \Theta_{i}$;

(ii) each buyer makes a non-negative expected profit:

$$
E_{\Theta_{i}}\left[\pi_{i}(\theta)\right]=E_{\Theta_{i}}\left[\left(R_{1}-I\right) x_{i}(\theta)+\theta\left[R_{0}-y_{i}(\theta)\right]-z_{i}(\theta)\right] \geq 0
$$

(iii) were a buyer to deviate from his offer, there would exist an allocation of seller types that is individually rational for the seller (in the sense of $(i)$ ) and such that the buyer does not benefit from the deviation.

Note that the budget balance condition at the individual buyer level implies that the industry as a whole makes a non-negative profit:

$$
E_{\Theta_{m}}[\pi(\theta)] \geq 0
$$

\footnotetext{
${ }^{15}$ There is a one-to-one mapping between $\Theta_{m}$ and $F_{m}(\cdot)$.
} 
where $\pi(\theta)$ is the profit made by the industry on type $\theta$.

Definition 4. (equilibrium). Consider an incentive compatible intervention with resulting utility schedule $\left\{U_{g}(\cdot)\right\}$. An equilibrium is an allocation of types

$$
\Theta_{g} \cup \Theta_{m}=[0,1] \text { and } \Theta_{g} \cap \Theta_{m}=\emptyset,
$$

and associated market equilibrium with resulting utility schedule $\left\{U_{m}(\cdot)\right\}$ corresponding to the equilibrium allocation for posterior beliefs defined by $\Theta_{m}$, such that

$$
\left\{\begin{array}{l}
U_{m}(\theta)>U_{g}(\theta) \quad \Longrightarrow \theta \in \Theta_{m} \\
U_{g}(\theta)>U_{m}(\theta) \Longrightarrow \theta \in \Theta_{g} .
\end{array}\right.
$$

An "outcome" or "allocation" will from now on refer to the real allocation $\{x(\cdot), U(\cdot)\}$ and not to the financial transfers giving rise to this allocation.

Lemma 1. If the equilibrium outcome is trivial, then $U(\theta)=U_{0}(\theta)$ for all $\theta$.

A trivial mechanism creates no gain from trade. The proof of Lemma 1 is omitted, as it closely follows that of the no-trade theorem (e.g., Paul Milgrom and Nancy Stokey 1982).

\section{Buybacks only}

Let us first assume that the government and the market can only offer to buy the asset. Buybacks correspond to an extreme case in which none of the cash flow $R_{0}$ attached to the legacy asset can be appropriated by non-owners. ${ }^{16}$ Thus the seller keeps either no skin in the game (contract with the government or with buyers) or a full share in the legacy asset (autarky). This case, besides its simplicity and its applications to various buyback and credit guarantee schemes, enables a clean analysis of the similarities and the differences with Coase's (1972) model of the durable good monopolist.

The timing goes as follows: First, the government offers to purchase the legacy asset at price $p_{g}$. Sellers then choose whether to accept the government's offer. Second, the market (which

\footnotetext{
${ }^{16}$ Technically, a buyback offer satisfies $y_{i}(\theta)=0$ for all $\theta$. By incentive compatibility $z_{i}(\theta)=\widehat{z}_{i} \geq B-b$ if $x_{i}(\theta)=1$ and $z_{i}(\theta)=\widehat{t}_{i}$ if $x_{i}(\theta)=0$. Furthermore, it can be shown that optimal buyer behavior implies that the seller receives $\widehat{t}_{i}=0$ in the absence of investment. Note that the offer $\widehat{z}_{i}$ associated with investment is equivalent to a purchase of the asset at price $p_{i}=\widehat{z}_{i}+b-S \geq B-S$, and letting the seller be financed on the market (which is doable since $p_{i}+S-B \geq 0$ ); in either case the seller receives utility $\widehat{z}_{i}+b=p_{i}+S$ (under the former policy, the seller receives on top of $\widehat{z}_{i}$ private benefit $b$ ). We will without loss of generality assume that the buyers offer to purchase the asset and that the resulting monetary transfer serves as equity for new financing.
} 
exists only for those seller types who have turned down the government's offer) clears at some price $p_{m}$.

\section{A. Laissez-faire}

In the absence of government intervention, the market breaks down $\left(p_{m}=0\right)$ if there exists no price $p$ satisfying the following two conditions:

(i) "equity" $p$ enables financing:

$$
p+[S-B] \geq 0
$$

(ii) buyers break even:

$$
p \leq E\left[\theta R_{0} \mid \theta R_{0} \leq p+S\right] \equiv m^{-}\left(\frac{p+S}{R_{0}}\right) R_{0}
$$

In order for a market to deliver something else than autarky, there must be gains from trade. Condition (i) says that a seller who collects $p$ from the sale of her legacy asset and therefore has "equity" or "net worth" $p$ to invest in the new project overcomes the shortage of pledgeable income hampering the financing of the new project. Thus, suppose that $p+[S-B] \geq 0$ and so trading the legacy asset generates gains from trade $S$ (the net surplus attached to the new project goes to the seller as the financial market is competitive). The seller then parts with her asset if her resulting welfare, $p+S$, exceeds the autarky utility $\theta R_{0}$. Condition (ii), in which $m^{-}$denotes the truncated mean, is the buyer's breakeven condition in the market for the legacy asset.

Conversely, if there are prices satisfying (i) and (ii), then the equilibrium price is the highest such price, namely the one that satisfies (ii) with equality. This price is unique since the derivative of the RHS in (ii) is $\left(m^{-}\right)^{\prime}<1$ from log-concavity. To sum up, letting $\widetilde{p}$ satisfy $\widetilde{p}=m^{-}\left((\widetilde{p}+S) / R_{0}\right) R_{0}$, the equilibrium price under laissez-faire is $p_{m}^{\ell f}=0$ if $\widetilde{p}<B-S$ and $p_{m}^{\ell f}=\widetilde{p}$ if $\widetilde{p} \geq B-S$.

Market freeze. Index the distribution $F$ by a "good-news parameter" $\gamma: F(\theta \mid \gamma)$. A higher $\gamma$ means a better distribution in the sense of first-order stochastic dominance. Let $\gamma_{0}$ be such that the market price is equal to $B-S$, the threshold at which the project is financed: $m^{-}\left(B / R_{0}, \gamma_{0}\right) R_{0}=$ 
$B-S$. Thus for $\gamma \geq \gamma_{0}$, the volume of trade is $F\left((\widetilde{p}+S) / R_{0} \mid \gamma\right)$. This volume of trade as well as the market price fall to 0 for $\gamma<\gamma_{0}$. The market completely freezes as $\gamma$ falls just below $\gamma_{0}$.

\section{B. Government intervention}

Let the government now offer to buy the asset at some price $p_{g} \cdot{ }^{17}$ We focus on "relevant interventions":

Definition 5. : A government intervention is relevant if it exceeds the market price under laissez faire $\left(p_{g}>p_{m}^{\ell f}\right)$, and it enables some financing ${ }^{18}\left(p_{g} \geq B-S\right)$.

Non-relevant interventions yield the same outcome and welfare as laissez-faire. Consider therefore a relevant intervention. The equilibrium market price $p_{m}$ cannot strictly exceed $p_{g}$ : Otherwise no seller would accept the government's offer, and so $p_{m}=p_{m}^{\ell f} \leq p_{g}$, a contradiction.

Suppose, conversely, that in equilibrium $p_{m}<p_{g}$. Then types $\Theta_{g}=\left\{\theta \leq \theta_{g}\right\}$ accept the government's offer, with $\theta_{g} R_{0}=p_{g}+S$. Types $\Theta_{m}=\left(\theta_{g}, 1\right]$ remain in the market place, although they don't trade. However, type $\theta_{g}$ is profitable at price $p_{g}: \theta_{g} R_{0}-p_{g}=S>0$, and so are all types above $\theta_{g}$. Furthermore offers a bit above $p_{g}$ are accepted. So the market does not shut down, a contradiction. Thus the equilibrium necessarily involves price equalization: $p_{m}=p_{g}$.

From now on, we will assume, without loss of generality, that $p_{g} \leq R_{0}-S$. Indeed suppose that $p_{g}>R_{0}-S$. Then all sellers participate in the scheme as $p_{g}+S>R_{0}$. Furthermore, the intervention is unnecessarily costly as lowering $p_{g}$ a bit would still keep every type on board. ${ }^{19}$ Note in passing that this also implies that financing all types is never optimal for the government, as a price slightly below $R_{0}-S$ keeps every type financed (once the market

\footnotetext{
${ }^{17}$ This asset repurchase intervention admits several, equivalent interpretations. Instead of acquiring the assets, the authorities could, as was recommended to revive securitization, introduce credit guarantees or insurance to cover underlying assets. Insured assets then sell at $R_{0}$ in the market, and so the issuer receives an equivalent $p_{g}=R_{0}-\phi$ if $\phi$ is the fee charged by the government for the guarantee. Another implementation (if arbitrage can be prevented) is a transaction subsidy $\tau$. Then the market yields price $p$ such that $\tau+p+[S-B]=0$ and $p=E\left[\theta R_{0} \mid \theta R_{0} \leq \tau+p+S\right]$. Yet another scheme ("TARP style") consists in announcing a certain amount to be spent by the government.

${ }^{18}$ The idea that intervention requires a minimum scale resonates with the recent experience in securitization markets. Despite extensive intervention by central banks and governments to buy securitized assets directly or lend against them, most market segments have not witnessed a revival of private sector investment in such assets.

${ }^{19}$ More formally, and using the market's zero-profit condition, welfare is $W=(1+\lambda)\left[E[\theta] R_{0}+S\right]-\lambda\left(p_{g}+S\right)$, and so a small reduction in $p_{g}$ increases welfare.
} 
rebound is accounted for). Similarly we will assume that $p_{m}^{\ell f}<R_{0}-S$, otherwise there would be no reason for the government to intervene.

Let us now describe an equilibrium; we will treat uniqueness later. In this equilibrium, types $\left[0, \theta_{g}\right]$ accept the government's offer, while types $\left[\theta_{g}, \theta^{*}\right]$ are financed by the market where $\theta^{*} R_{0}=p_{g}+S$, and $\theta_{g}$ is given by

$$
p_{g}=m\left(\theta_{g}, \frac{p_{g}+S}{R_{0}}\right) R_{0} \equiv H\left(\theta_{g}, p_{g}\right)
$$

letting $m\left(\theta^{-}, \theta^{+}\right)$denote the mean of the distribution when it is left-truncated at $\theta^{-}$and righttruncated at $\theta^{+}$, for any $\theta^{-} \leq \theta^{+}{ }^{20}$ Note that $\partial H / \partial p_{g}=\partial m / \partial \theta^{+}<1$, since $\partial m / \partial \theta^{+}<1$ from the log-concavity of $F .^{21}$

Proposition 1. (description of equilibrium) Consider (without loss of generality) a relevant government intervention $\left(p_{g} \geq B-S\right.$, and $\left.p_{g}>p_{m}^{\ell f}\right)$. Then

(i) there exists a unique equilibrium market price. The market price $p_{m}$ equates the government's price: $p_{m}=p_{g}$;

(ii) types in $\left[0, \theta^{*}\right]$ part with their asset and finance the new project, with $\theta^{*}=\frac{p_{g}+S}{R_{0}}$. Types in $\left(\theta^{*}, 1\right]$ keep their asset and are not financed;

(iii) the following describes an equilibrium behavior: types in $\left[0, \theta_{g}\right)$ join the government's scheme, and types in $\left[\theta_{g}, \theta^{*}\right]$ sell their legacy asset in the free market, where $\theta_{g}$ is uniquely defined by: $p_{g}=p_{m}=m\left(\theta_{g}, \theta^{*}\right) R_{0}$;

(iv) furthermore the equilibrium described in (iii) is the unique equilibrium behavior in the limit of vanishingly small probability that either an exogenous event forces the market to shut down after decisions to join the government's scheme have been made, or that the seller's type is revealed to the market before the latter opens (i.e., between stages 3 and 4);

\footnotetext{
${ }^{20}$ That is, $m\left(\theta^{-}, \theta^{+}\right) \equiv\left[\int_{\theta^{-}}^{\theta^{+}} \theta d F(\theta)\right] /\left[F\left(\theta^{+}\right)-F\left(\theta^{-}\right)\right]$.

${ }^{21}$ See e.g., An (1988). We here make use of the fact that the left-truncated distribution $\widehat{F}(\theta) \equiv[F(\theta)-$ $\left.F\left(\theta_{g}\right)\right] /\left[1-F\left(\theta_{g}\right)\right]$ inherits the log-concavity of $F$.
} 
(v) it is never optimal for the government to finance all types that receive financing.

To prove (iv), suppose that there is an arbitrarily small probability $\varepsilon$ that an exogenous event forces the market to shut down just after government offers are accepted or refused or that the true type is revealed to the market before the latter opens. Then sorting prevails: higher $\theta$ types have a (small) relative preference for the market. And so a cutoff indeed exists. ${ }^{22}$

The equilibrium allocation is summarized in Figure 2.

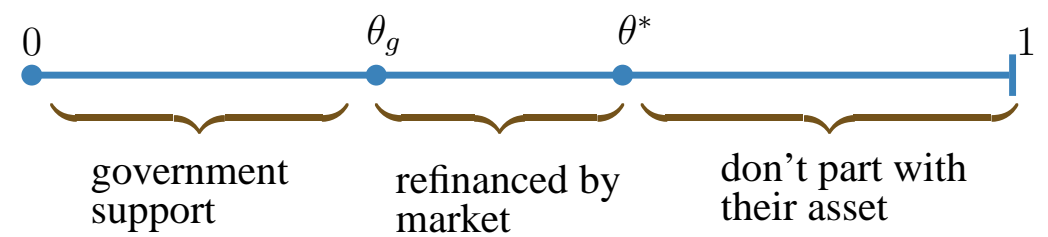

Figure 2: equilibrium outcome under buybacks

Let us next turn to the government's optimal policy. Recall that the government's objective is $W=E[U(\theta)]-(1+\lambda) D$, where $\lambda$ is the shadow cost of public funds and $D$ the deficit.

Proposition 1 implies that if the government wants to induce a cutoff $\theta^{*}$ below which the seller is refinanced, it cannot aim at a comprehensive intervention: Were $\theta_{g}=\theta^{*}$, then types above $\theta^{*}$ would actually be refinanced by the market. Put differently, an intervention that is successful in facilitating refinancing must be expensive: It must yield government-rescued sellers $\left(\theta \in\left[0, \theta_{g}\right)\right)$ utility $U_{0}\left(\theta^{*}\right)$ and not just $U_{0}\left(\theta_{g}\right)$.

The following proposition first compares the outcome with the one that prevails when the government can shut down market transactions, but must respect private property ("no expropriation": the seller can refuse to participate and must therefore enjoy utility at least $U_{0}(\theta)$ ). The proposition then characterizes the optimal intervention. Finally, it observes that the intervention loses money on all financed types.

\section{Proposition 2. (optimal intervention)}

\footnotetext{
${ }^{22}$ Assume for example that with vanishingly small probability $\varepsilon$, bad news accrue as to the probability of success decreases: The distribution shifts from $F\left(\cdot \mid \gamma_{1}\right)$ to $F\left(\cdot \mid \gamma_{2}\right)$ with $\gamma_{2}<\gamma_{1}$. The shock is sufficiently strong that the market breaks down. And so type $\theta$ prefers the market to the government if and only if:

The proof is straightforward.

$$
p_{g}+S<(1-\varepsilon)\left(p_{m}+S\right)+\varepsilon E_{F\left(\cdot \mid \gamma_{2}\right)}\left[U_{0}(\widetilde{\theta}) \mid \theta\right] .
$$
}


(i) The presence of a free market does not reduce social welfare relative to when the government has the power to shut down the market, but not to expropriate the seller, provided that the government anticipates that it creates its own competition by rejuvenating the market. The intervention should not be comprehensive.

(ii) Suppose first that there is no market breakdown $\left(p_{m}^{\ell f} \geq B-S\right)$. Then, there exist $\lambda_{1}$ and $\lambda_{2}\left(0<\lambda_{1}<\lambda_{2}<+\infty\right)$ such that the optimal policy involves: For $\lambda \leq \lambda_{1}$, all types are financed: $\theta^{*}=1$. For $\lambda_{1} \leq \lambda \leq \lambda_{2}$, the optimal financing scope is given by an efficiency/rent-extraction trade-off:

$$
f\left(\theta^{*}\right)(1+\lambda) S=F\left(\theta^{*}\right) \lambda R_{0}
$$

For $\lambda>\lambda_{2}$, the government does not intervene.

(iii) In case of market breakdown $\left(p_{m}^{\ell f}=0\right)$, the government intervenes iff $\lambda \leq \lambda_{3}$ for some $\lambda_{3}$. A small intervention can then have large effects.

(iv) When intervening the government overpays with probability 1.

Proof: The government chooses a cutoff $\theta^{*}$, or equivalently a price $p\left(=p_{g}=p_{m}\right)$ satisfying $p+S=U_{0}\left(\theta^{*}\right)$, assuming that $\theta^{*} R_{0} \geq B$, so this leads to some financing. Using the buyers' zero-profit condition (and so $\left[p-m^{-}\left(\theta_{g}\right) R_{0}\right] F\left(\theta_{g}\right)=\left[p-m^{-}\left(\theta^{*}\right) R_{0}\right] F\left(\theta^{*}\right)$ ), social welfare under a non-trivial government intervention is the same as when the market is prohibited:

$$
W=(p+S) F\left(\theta^{*}\right)+\int_{\theta^{*}}^{1} U_{0}(\theta) d F(\theta)-(1+\lambda)\left[p-m^{-}\left(\theta^{*}\right) R_{0}\right] F\left(\theta^{*}\right) .
$$

Replacing $p$ by $\left[\theta^{*} R_{0}-S\right]$, it is easy to check that $\partial^{2} W / \partial \lambda \partial \theta^{*}<0$, and so the optimal $\theta^{*}$ must be a non-increasing function of $\lambda .^{23}$ Using the expression for the derivative of the truncated mean

$$
\frac{d m^{-}\left(\theta^{*}\right)}{d \theta^{*}}=\frac{d}{d \theta^{*}}\left[\frac{\int_{0}^{\theta^{*}} \theta d F(\theta)}{F\left(\theta^{*}\right)}\right]=\frac{f\left(\theta^{*}\right)}{F\left(\theta^{*}\right)}\left[\theta^{*}-m^{-}\left(\theta^{*}\right)\right]
$$

\footnotetext{
${ }^{23}$ The private sector's profit under laissez-faire, written as a function of $\theta^{*}$ is $\pi\left(\theta^{*}\right) \equiv F\left(\theta^{*}\right)\left[m^{-}\left(\theta^{*}\right) R_{0}-\right.$ $\left(\theta^{*} R_{0}-S\right)$ ], with $\pi^{\prime}\left(\theta^{*}\right)=f\left(\theta^{*}\right) S-F\left(\theta^{*}\right) R_{0}$. With a log-concave distribution, $\pi\left(\theta^{*}\right)$ first increases (starting from 0 ) and then decreases. In particular, at the market equilibrium, it is always the case that $f\left(\theta^{*}\right) S<F\left(\theta^{*}\right) R_{0}$.
} 
and substituting for $p$, one obtains, in the case of an interior cutoff:

$$
\frac{\partial W}{\partial \theta^{*}}=-F\left(\theta^{*}\right) \lambda R_{0}+f\left(\theta^{*}\right)(1+\lambda) S
$$

Because the distribution $F$ is log-concave, there is at most one solution to equation (2). If $\partial W / \partial \theta^{*}>0$ for all $\theta^{*}<1$, then $\theta^{*}=1$. Finally, when the free market freezes, a corner solution may also occur if the value $\theta^{*}$ given by the first-order solution does not enable financing:

$$
p+S-B=U_{0}\left(\theta^{*}\right)-B<0 .
$$

The optimal intervention is then either not to intervene $\left(\theta^{*}=0\right)$ or to intervene at a scale consistent with financing $\left(\theta^{*} \geq B / R_{0}\right){ }^{24}$

Condition (2) also shows that interventions are more extensive ( $\theta^{*}$ increases) if public interventions are not too costly (the shadow cost of public funds decreases, or equivalently seller's welfare receives a higher weight in the social welfare function).

Small bad news. As earlier, let us index the distribution $F$ by a parameter $\gamma,{ }^{25}$ and let $\gamma_{0}$ denote the level of $\gamma$ such that the market freezes when $\gamma<\gamma_{0}$. Suppose that initially $\gamma=\gamma_{0}+\varepsilon$ (with $\varepsilon$ small and positive). Then there is no intervention or an intervention depending on the level of $\lambda$ (see above). Now suppose that small bad news bring $\gamma$ to $\gamma_{0}-\varepsilon$. Then for any $\lambda$, for $\varepsilon$ sufficiently small, it is optimal to intervene. Furthermore, a low-cost intervention has a large impact on social welfare: jumpstarting the market involves a vanishingly small deficit $D$ as $\varepsilon$ goes to 0 , while having an impact on utilities $E[U(\theta)]$ converging to $\int_{0}^{\theta^{*}}\left(\theta^{*}-\theta\right) R_{0} d F\left(\theta \mid \gamma_{0}\right)$ (with $\left.\theta^{*}=B / R_{0}\right)$.

Note, finally, that $p_{g}=m\left(\theta_{g}, \theta^{*}\right) R_{0}>\theta R_{0}$ for all $\theta \leq \theta_{g}$. Hence, the government overpays with probability 1 .

\footnotetext{
${ }^{24}$ There is no intervention for $\lambda>\bar{\lambda}$, where $\bar{\lambda}$ is such that the increase in rents for types in $\left[0, \theta^{*}=B / R_{0}\right]$ is equal to the deficit cost of repurchasing the asset at price $p=B-S$ from these types:

$$
\int_{0}^{\theta^{*}}\left[B-U_{0}(\theta)\right] d F(\theta)=(1+\bar{\lambda})\left[B-S-m^{-}\left(\theta^{*}\right) R_{0}\right] F\left(\theta^{*}\right) .
$$

${ }^{25}$ Rather than moving the distribution, we could move the surplus $S$. Assuming that agency costs do not increase too fast with $S$ (technically $d B / d S<1 /\left[1-\left(m^{-}\right)^{\prime}\right]$ ), which is reasonable, a reduction in $S$ reduces the volume of trade in the legacy asset and may cause a freeze.
} 
Remark. By contrast, assuming that ${ }^{26} F(\theta \mid \gamma) \equiv G(\theta-\gamma)$, then as long as the free market does not break down, the two sides of the no-intervention condition, $\lambda R_{0} G\left(\theta_{m}^{\ell f}-\gamma\right) \geq(1+$ $\lambda) S g\left(\theta_{m}^{\ell f}-\gamma\right)$, are invariant with $\gamma$. And so in the no-breakdown region, news do not affect the incentive to intervene.

\section{Ex-ante moral hazard}

Finally, it can be shown (see supplementary material) that when the distribution of $\theta$ is determined by an ex-ante effort, ${ }^{27}$ this effort is reduced by the prospect of government intervention.

Furthermore, if the government could commit to a price $p_{g}$ before the effort is chosen, then $p_{g}$ would be smaller (the intervention would be less extensive) than in the absence of commitment. However this policy is time inconsistent: Authorities would want ex post to raise the price to the level implied by (2). Anticipating this, the firms would behave as in the absence of commitment.

\section{General sharing schemes in the market}

When the return $R_{0}$ on the legacy asset is contractible and can be shared, buybacks only in general is no longer optimal. We now generalize the previous analysis to arbitrary sharing schemes. We first consider the free market outcome, but for an arbitrary posterior distribution $\Theta_{m}$ (with corresponding cumulative distribution $F_{m}(\cdot)$ ). We thereby study the "continuation game" that will be used in Section IV. to analyze what happens in the market once a subset of types have been sorted out by the government's intervention. A special case of the analysis $\left(F_{m}=F\right)$ will give us the laissez-faire allocation.

Let

$$
V(\theta y) \equiv \max \{B, b+\theta y\}
$$

$V(\theta y)$ corresponds to the expected utility obtained by a seller of type $\theta$ who receives no fixed

\footnotetext{
${ }^{26}$ The distribution of $\theta$ then has support $[\gamma, \bar{\theta}+\gamma]$ for some $\bar{\theta}$. The free market outcome is given, after an integration by parts, by:

$$
\int_{0}^{\theta_{m}^{\ell f}-\gamma} G(\theta-\gamma) d \theta=\frac{S}{R_{0}} G\left(\theta_{m}^{\ell f}-\gamma\right),
$$

and so $\theta_{m}^{\ell f}-\gamma$ is independent of $\gamma$ as long as $\theta_{m}^{\ell f} R_{0} \geq B$ (no market breakdown).

${ }^{27}$ Effort $e$ generates a distribution $F(\theta \mid e)$ satisfying $\partial(f / F) / \partial e>0$ and $\partial(f / F) / \partial \theta<0$.
} 
payment, pledges income $R_{0}-y$ on her legacy asset in order to finance her new project, and thus keeps skin in the game $y$. Indeed, once this new project has been financed, the seller can shirk and get $B$, or work and obtain $b+\theta y$. The IC implementation of the $V(\cdot)$ rent function involves a menu of two options: $\{\widehat{z}=0, \widehat{y}=y\}$ yielding utility $b+\theta y$ to type $\theta$, and $\{\widehat{z}=B-b, \widehat{y}=0\}$ yielding utility $B$ for all types.

Consider the following condition for a given $y$ :

$$
\Pi(y) \equiv \int_{\left\{\theta \text { s.t. } V(\theta y) \geq U_{0}(\theta)\right\}}\left[\theta R_{0}+S-V(\theta y)\right] d F_{m}(\theta) \geq 0 .
$$

The motivation for introducing this function stems from the following lemma, which plays a central role in the subsequent analysis.

Lemma 2. Consider an arbitrary incentive compatible mechanism with investment function $x(\cdot)$ and rent function $U(\cdot)$. Let $y$ denote the highest skin in the game among types who invest: $y \equiv \sup _{\{\theta \mid x(\theta)=1\}}\{y(\theta)\}$, and $\widetilde{\theta} \equiv \sup \{\theta \mid x(\theta)=1\}$. Let $\theta^{*} \equiv \inf \left\{\theta \mid U(\theta)=U_{0}(\theta)\right\} .{ }^{28}$ Then,

(i) $x(\theta)=0$ and $U(\theta)=U_{0}(\theta)$ for all $\theta>\theta^{*}$; and

(ii) there exists $\stackrel{v}{y} \geq y$ and $\stackrel{v}{\theta} \in\left[\widetilde{\theta}, \theta^{*}\right]$ satisfying $b+\stackrel{v}{\theta} y=U_{0}(\stackrel{v}{\theta})$ such that the buyer profit on this mechanism is at most $\int_{0}^{v}\left[S+\theta R_{0}-V(\theta v)\right] d F_{m}(\theta)$.

Proof of Lemma 2:

(i) Consider a type $\theta>\theta^{*}$. Then incentive compatibility implies that: $b x(\theta)+z(\theta)+\theta y(\theta) \geq U_{0}(\theta)$ and $b x(\theta)+z(\theta)+\theta^{*} y(\theta) \leq U_{0}\left(\theta^{*}\right)$, and so

$$
\left(\theta-\theta^{*}\right)\left[y(\theta)-R_{0}\right] \geq 0
$$

with strict inequality if type $\theta$ gets strictly more than his reservation utility. ${ }^{29}$ But type $\theta^{*}$ must prefer her allocation to that of type $\theta$, and so

$$
\theta^{*}\left[R_{0}-y(\theta)\right] \geq b x(\theta)+z(\theta)
$$

Thus

$$
y(\theta)=R_{0} \quad \text { and } \quad x(\theta)=z(\theta)=0 .
$$

\footnotetext{
${ }^{28}$ Schemes in which $U(\theta)>U_{0}(\theta)$ for all $\theta$ are suboptimal and therefore not considered here.

${ }^{29}$ Intuitively, at $\theta^{*}$ the right-derivative of $U(\cdot)$ must (weakly) exceed $R_{0}$ in order to keep $U(\theta) \geq \theta R_{0}$ satisfied to the right of $\theta^{*}$. The convexity of $U(\cdot)$ then implies that $y(\theta)$ (weakly) exceeds $R_{0}$ above $\theta^{*}$.
} 
(ii) Let $\stackrel{\vee}{\theta}$ be defined by $b+z(\widetilde{\theta})+\stackrel{v}{\theta} y=U_{0}(\stackrel{v}{\theta})$. From the convexity of $U(\cdot), \stackrel{v}{\theta} \in\left[\widetilde{\theta}, \theta^{*}\right]$.

Because there are no gains from trade for $\theta \geq \widetilde{\theta}$ and a fortiori for $\theta \geq \stackrel{v}{\theta}$, buyer profit is bounded above by:

$$
\int_{0}^{\vee}\left[\theta R_{0}+S-U(\theta)\right] d F_{m}(\theta) \leq \int_{0}^{\vee}\left[\theta R_{0}+S-\max \{B, b+z(\widetilde{\theta})+\theta y\}\right] d F_{m}(\theta) .
$$

Let $y \geq y$ be defined by

$$
b+\stackrel{\vee}{\theta} \stackrel{v}{y} \equiv b+z(\widetilde{\theta})+\stackrel{v}{\theta} y
$$

Because $b+\theta \stackrel{v}{y} \leq b+z(\widetilde{\theta})+\theta y$ for $\theta \leq \stackrel{v}{\theta}$, the profit is bounded above by

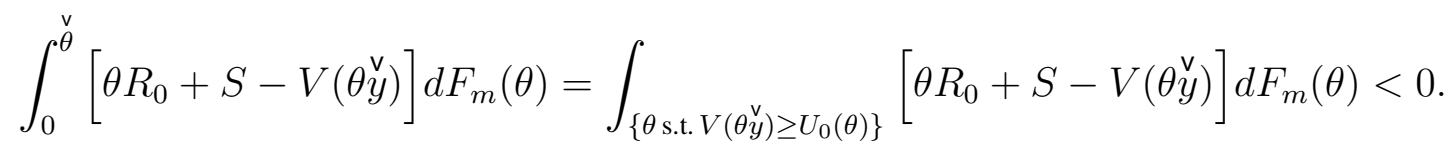

Assumption 4. $\Pi\left(R_{0}-b\right)<0$.

Were Assumption 4 violated, then the market would function perfectly, in that all types would be financed (this is a consequence of the following analysis). So there would be no benefit from government intervention.

Lemma 3. Consider a non-trivial equilibrium. And let

$y \equiv \sup _{\{\theta \mid x(\theta)=1\}}\{y(\theta)\}$. Then $y<R_{0}-b$.

In particular, the skin in the game can never exceed its no-trade level $R_{0}$.

Proof: This is just a consequence of Assumption 4 and the fact that $U(\theta) \geq \max \left\{V(\theta y), U_{0}(\theta)\right\}:$ For $y>R_{0}-b, b+\theta y>\theta R_{0}$ (the reservation utility is not binding for any type) for all $\theta$ and so

$$
\Pi(y)=\int_{0}^{1}\left[\theta R_{0}+S-V(\theta y)\right] d F_{m}(\theta) .
$$

Letting $\theta_{0}(y)$ be defined by

$$
B=b+\theta_{0}(y) y
$$

one has

$$
\Pi^{\prime}(y)=\int_{\theta_{0}(y)}^{1}(-\theta) d F_{m}(\theta)<0 .
$$

So $\Pi(y)$ is decreasing whenever $y>R_{0}-b$. This, together with Assumption 4, implies that $\Pi(y)<0$ for all $y \geq R_{0}-b$. 


\section{Proposition 3. (market breakdown)}

If there exists no y satisfying (3), the unique equilibrium involves market breakdown: $U_{m}(\theta)=$ $U_{0}(\theta)$ for all $\theta$.

Proof: Proposition 3 is a direct corollary of Lemma 2 (ii).

Let us now investigate the outcome when the set of $y$ satisfying (3) is non-empty.

The (constrained) efficient allocation

Ignoring equilibrium considerations for the moment, let us look for the constrained efficient allocation, which is the one maximizing total (net) surplus

$$
E_{\Theta_{m}}[x(\theta) S]
$$

among those satisfying (IC) and (BB) ${ }^{30}$ If $\Pi(y)<0$ for all $y$, then the constrained efficient allocation is the autarky/market breakdown one. So suppose that the set of $y$ such that $\Pi(y) \geq 0$ is non-empty.

\section{Proposition 4. (constrained efficient allocation)}

Suppose that $\Pi(y) \geq 0$ for some $y$. Let $y_{m}$ denote the highest value such that $\Pi(y) \geq 0$. Among allocations that satisfy $(B B)$ and (IC), the constrained efficient one satisfies:

$$
\begin{aligned}
& U(\theta)=\max \left\{V\left(\theta y_{m}\right), U_{0}(\theta)\right\} \\
& \int_{0}^{\theta_{m}^{*}}\left[S+\theta R_{0}-V\left(\theta y_{m}\right)\right] d F_{m}(\theta)=0
\end{aligned}
$$

and

$$
x(\theta)=1 \quad \text { iff } \theta \leq \theta_{m}^{*}, \text { where } V\left(\theta_{m}^{*} y_{m}\right)=U_{0}\left(\theta_{m}^{*}\right) .
$$

Proof: Consider an arbitrary IC allocation and define $\{\stackrel{v}{\theta}, \stackrel{v}{y}\}$ as in the proof of Lemma 2. We know from the proof of Lemma 2 that

$$
x(\theta)=0 \text { for } \theta>\stackrel{\vee}{\theta}, \text { and } U(\theta) \geq \max \left\{V(\theta \stackrel{v}{y}), U_{0}(\theta)\right\} \text { for all } \theta .
$$

\footnotetext{
${ }^{30}$ This is also the allocation that would be selected by the seller and competitive buyers behind the veil of ignorance (the seller does not yet know the realization of $\theta$ ) and under a seller ex post individual rationality constraint (the seller cannot commit to transfer the legacy asset).
} 
Thus buyer profit is bounded above by

$$
\int_{0}^{\stackrel{v}{\theta}}\left[\theta R_{0}+S-V(\theta \mathrm{v})\right] d F_{m}(\theta) .
$$

Total net surplus is bounded above by $F_{m}(\stackrel{v}{\theta}) S$, an increasing function of $\stackrel{v}{\theta}$. Thus, an upper bound on total net surplus is obtained by choosing the highest $\stackrel{v}{\theta}$ for which (4) is non-negative, namely $\theta_{m}^{*}$, as characterized in the statement of the proposition.

The second stage of the proof consists in showing that this upper bound can indeed be reached. For this, it suffices to note that the mechanism $\{x(\theta)=1, z(\theta)=B-b$ and $y(\theta)=0$ for $\theta$ s.t. $\theta y_{m}+b \leq B ; x(\theta)=1, z(\theta)=0$ and $y(\theta)=y_{m}$ for $\theta$ s.t. $\left.\theta y_{m}+b>B\right\}$ is incentive compatible and attracts all types below $\theta_{m}^{*}$ and none above.

The constrained efficient allocation is depicted in Figure 3.

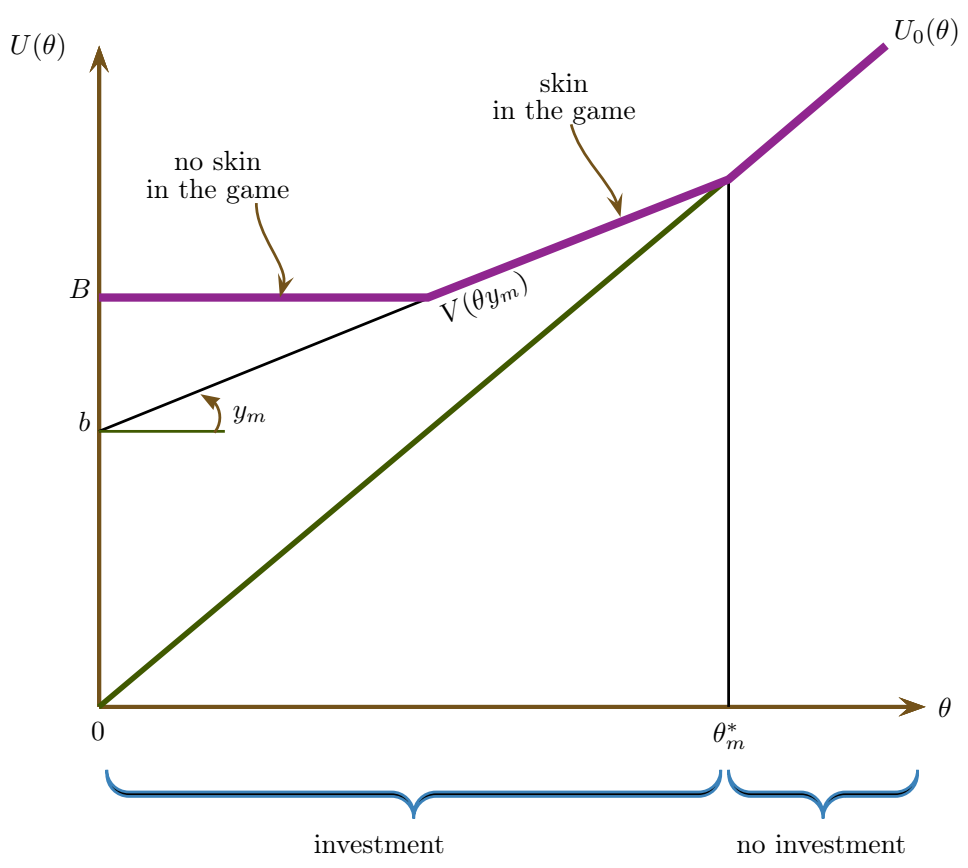

Figure 3: The constrained efficient allocation

Lemma 4. In the constrained efficient allocation:

(i) $y_{m}<R_{0}$,

(ii) the buyers' type-contingent profit $\pi(\theta)$ is strictly increasing in $\theta$ for $\theta<\theta_{m}^{*}$.

Proof: (i) From Assumption 4, $y_{m}<R_{0}-b$, and so $y_{m}<R_{0}$. 
(ii) One has

$$
\int_{0}^{\theta_{m}^{*}}\left[S+\theta R_{0}-V\left(\theta y_{m}\right)\right] d F_{m}(\theta)=0
$$

and so, letting $\theta_{0}$ be defined by $b+\theta_{0} y_{m}=B$, one has

$$
\pi(\theta)=S+\theta R_{0}-B \text { for } \theta \leq \theta_{0} \text {, and }=S-b+\theta\left(R_{0}-y_{m}\right) \text { for } \theta \in\left[\theta_{0}, \theta_{m}\right]
$$

Thus, $\pi^{\prime}(\theta)=\left\{\begin{array}{l}R_{0} \text { when } V\left(\theta y_{m}\right)=B \\ R_{0}-y_{m}>0 \text { when } V\left(\theta y_{m}\right)=b+\theta y_{m} .\end{array}\right.$

We now show that the constrained efficient allocation is an equilibrium outcome. ${ }^{31}$

\section{Proposition 5. (existence). The constrained efficient allocation is an equilibrium outcome.}

Proof: Let all buyers offer the constrained efficient allocation and thereby attract a representative sample of the population. ${ }^{32}$ A deviating buyer cannot make a profit by offering a trivial mechanism, which would create no gains from trade if the offer were taken up. Suppose therefore that a buyer offers a non-trivial, incentive compatible mechanism with utilities $U^{* *}(\cdot)$, while equilibrium utilities are the piecewise linear $U^{*}(\cdot)$ as in the constrained efficient allocation. Because the mechanism is non-trivial, $U^{* *}(\theta) \geq B$ for all $\theta$. Let $\theta^{* *} \equiv \inf \left\{\theta \mid U^{* *}(\theta)=\right.$ $\left.U_{0}(\theta)\right\}$. If $\theta^{* *} \geq \theta_{m}^{*}$, the convexity of $U^{* *}$ and the fact that the mechanism is non-trivial imply that:

Either (i) $U^{* *}(\theta) \geq U^{*}(\theta)$ for all $\theta \leq \theta^{* *}$, and so for all $\theta \in(0,1]$. Furthermore $x^{* *}(\theta)=0$ for $\theta>\theta^{* *}$. Let all seller types select the deviating buyer's offer. The deviating buyer's profit is bounded above by $\int_{0}^{\theta^{* *}}\left[\theta R_{0}+S-U^{* *}(\theta)\right] d F_{m}(\theta)$, which is non-positive from the constrained efficiency of $U^{*}(\cdot)$.

Or (ii) $U^{* *}(\theta) \geq U^{*}(\theta)$ for $\theta \in\left[0, \theta_{1}\right], U^{* *}(\theta)<U^{*}(\theta)$ on $\left(\theta_{1}, \theta_{2}\right)$, and $U^{* *}(\theta) \geq U^{*}(\theta)$ for $\theta \in\left[\theta_{2}, \theta^{* *}\right]$ with $\theta_{2}>\theta_{1}$. The latter implies that $x^{* *}(\theta)=0$ for $\theta \in\left(\theta_{2}, \theta^{* *}\right]$, because otherwise (i) would obtain: Indeed, suppose that $x^{* *}(\theta)=1$ for some $\theta>\theta_{2}$. Then because

\footnotetext{
${ }^{31}$ Thus, and in contrast with Rothschild-Stiglitz (1976), an equilibrium exists. In Rothschild-Stiglitz, like in this paper (in the region where investment is financed), screening operates through asking the seller to keep some skin in the game. Here, however, screening through revenue sharing does not involve any inefficiency; relatedly, it is never profitable to entice a high type to pool with a low one and possibilities for screening for the high types are limited due to the structure of the problem.

${ }^{32}$ One could have in mind the limit of a symmetric model of type-independent buyer differentiation (as in Rochet-Stole 2002) as the differentiation converges to 0 .
} 
$U^{* *}$ is convex, $d U^{* *}(\theta) / d \theta=y(\theta) \geq y_{m}$ and so

$$
U^{* *}(\theta) \geq U^{*}(\theta) \text { on }\left(\theta_{1}, \theta_{2}\right)
$$

as well, a contradiction. The mechanism may also attract some types $\theta>\theta^{* *}$, but we know that such types do not bring in any profit as $x^{* *}(\theta)=0$ from Lemma 2. So the mechanism cannot make money from the seller on $\left[\theta_{2}, 1\right]$ and does not attract types in $\left(\theta_{1}, \theta_{2}\right)$. If $U^{* *}(\cdot)=U^{*}(\cdot)$ on $\left[0, \theta_{1}\right]$, let the seller not accept the deviating buyer's offer when $\theta \in\left[0, \theta_{2}\right]$; the deviating buyer then makes a non-positive profit. If $U^{* *}(\theta)>U^{*}(\theta)$ on $\left[\theta_{3}, \theta_{1}\right]$ and $U^{* *}(\theta)=U^{*}(\theta)$ on $\left[0, \theta_{3}\right]$ with $0 \leq \theta_{3}<\theta_{1}$, then let all seller types in $\left[0, \theta_{1}\right]$ select the deviating buyer. However, because profit is increasing in type in the zero-profit, constrained efficient allocation (Lemma 4) and rents are higher on $\left[0, \theta_{1}\right]$ in the $U^{* *}(\cdot)$ allocation, again the deviating buyer makes a non-positive profit.

Finally, when $\theta^{* *}<\theta_{m}^{*}$, the proof in part (ii) of the case $\theta^{* *} \geq \theta_{m}^{*}$ still applies and so, again, the deviating buyer cannot make a positive profit.

\section{Equilibrium selection}

In Section IV., we will take the constrained efficient outcome to be the continuation equilibrium of the subform in which the seller has decided not to accept the government's offer and the market assigns posterior beliefs $F_{m}(\cdot)$ to the seller's type. Although this selection may involve a slightly optimistic view of how markets function, this equilibrium is the unique equilibrium outcome under the following "robust choice" refinement:

Robust choice: Consider two IC utility schedules $U(\cdot)$ and $\widehat{U}(\cdot)$. Suppose that $\widehat{U}\left(\theta_{0}\right)=$ $U\left(\theta_{0}\right)$, that $\widehat{U}(\theta) \geq U(\theta)$ for all $\theta \in\left[0, \theta_{1}\right]$ where $\theta_{1} \geq \theta_{0}$ and that $\widehat{U}(\theta)>U(\theta)$ to the right of $\theta_{1}\left(\widehat{U}(\theta)>U(\theta)\right.$ on $\left[\theta_{1}, \theta_{2}\right]$ where $\left.\theta_{2}>\theta_{1}\right)$. Then type $\theta_{0}$ selects schedule $\widehat{U}(\cdot)$ over schedule $U(\cdot)$.

One motivation for this refinement goes as follows: Suppose that the seller faces vanishingly small uncertainty about her type such that $f\left(\theta \mid \theta_{0}\right) / f\left(\theta^{\prime} \mid \theta_{0}\right) \rightarrow 0$ for $\theta>\theta^{\prime} \geq \theta_{0}$. Then choosing $\widehat{U}(\cdot)$ dominates choosing $U(\cdot)$ before the limit is reached. Robust choice is thus (much stronger than, but) in the spirit of the elimination of weakly dominated strategies. From the proof of Proposition 5, the constrained efficient allocation is an equilibrium outcome consis- 
tent with robust choice. The following result shows that this is the unique such equilibrium allocation:

Proposition 6. Under robust choice, the unique equilibrium outcome is the constrained efficient outcome.

\section{Market rejuvenation}

\section{A. Description of government intervention}

The government builds a voluntary-participation mechanism. A mechanism consists in the choice of a subset $\Theta_{g}$ of types in $[0,1]$ who participate in the scheme, and for each type $\theta$ in $\Theta_{g}$, a financing decision $x_{g}(\theta) \in\{0,1\}$ for the new project, and fixed payment $z_{g}(\theta)$ (independent of the outcome of the legacy asset) and contingent payment $y_{g}(\theta)$ if the legacy project succeeds, both conditional on the new project succeeding if $x_{g}(\theta)=1$. The seller receives 0 if the new project is financed and fails.

Let $x_{m}(\theta) \in\{0,1\}$ describe the financing decision in the market for types in $\Theta_{m}$ and $x(\theta) \equiv x_{g}(\theta)$ if $\theta \in \Theta_{g}$, and $x(\theta) \equiv x_{m}(\theta)$ if $\theta \in \Theta_{m}$ (where $\Theta_{g} \cup \Theta_{m}=[0,1]$ and $\left.\Theta_{g} \cap \Theta_{m}=\emptyset\right)$.

A seller with type $\theta$ in $[0,1]$ derives utility $U_{g}(\theta)$ from participating in the government's scheme:

$$
U_{g}(\theta)=\sup _{\left\{\widehat{\theta} \in \Theta_{g}\right\}}\left\{z_{g}(\widehat{\theta})+\theta y_{g}(\widehat{\theta})+x_{g}(\widehat{\theta}) b\right\} .
$$

The function $U_{g}(\cdot)$ is increasing and convex. Incentive compatibility implies that

$$
U_{g}(\theta) \geq B \text { for all } \theta
$$

if there exists at least one type $\theta^{\prime}$ such that $x_{g}\left(\theta^{\prime}\right)=1$. An intervention that satisfies (5), (6) and $U_{g}(\theta) \geq U_{0}(\theta)$ for all $\theta$ is said to be non-trivial and incentive compatible.

\section{B. Optimal intervention: an upper bound on social welfare}

Our strategy will consist in, first, looking for an upper bound on social welfare and, second, showing that this upper bound can be implemented through a simple government intervention. 
We look at the combined (government plus market) allocation $\{x(\cdot), U(\cdot)\}$. As usual, let $\theta^{*}=$ $\inf \left\{\theta \mid U(\theta)=U_{0}(\theta)\right\}$. Obviously $\theta^{*} \leq 1$ (if $U(\theta)>U_{0}(\theta)$ for all $\theta$, reducing the rents $U(\cdot)$ by a uniform $\varepsilon$ would increase the upper bound while preserving incentive compatibility). From Lemma $2, x(\theta)=0$ for $\theta>\theta^{*}$. In order to maximize welfare below $\theta^{*}$ :

$x(\theta)=1$ and $U(\theta)=V(\theta y)$ for $\theta \leq \theta^{*}$ where, as earlier, $y \equiv \sup _{\{\theta \mid x(\theta)=1\}}\{y(\theta)\}$.

An upper bound on welfare is therefore:

$$
\bar{W}\left(\theta^{*}\right)=(1+\lambda)\left[S F\left(\theta^{*}\right)+E[\theta] R_{0}\right]-\lambda\left[\int_{0}^{\theta^{*}} V(\theta y) d F(\theta)+\int_{\theta^{*}}^{1} U_{0}(\theta) d F(\theta)\right],
$$

where $y \equiv y\left(\theta^{*}\right)$ must satisfy $V\left(\theta^{*} y\right)=U_{0}\left(\theta^{*}\right)$. [We will later show that for the optimal policy $\left.W=\bar{W}\left(\theta^{*}\right)\right]$.

Letting $\theta_{0}$ be defined by

$$
b+\theta_{0} y=B, \text { or } \theta_{0}\left(\theta^{*}\right) \equiv \frac{\theta^{*}(B-b)}{\theta^{*} R_{0}-b} .
$$

The rent is equal to $B$ below $\theta_{0}(y)$ and to $U_{0}(\theta)+b\left(1-\frac{\theta}{\theta^{*}}\right)$ between $\theta_{0}\left(\theta^{*}\right)$ and $\theta^{*}$. One has

$$
\frac{d \bar{W}}{d \theta^{*}}=(1+\lambda) S f\left(\theta^{*}\right)-\lambda \int_{\theta_{0}\left(\theta^{*}\right)}^{\theta^{*}} \frac{b \theta}{\left(\theta^{*}\right)^{2}} d F(\theta) .
$$

The first term in this derivative represents the efficiency gain from financing more types, while the second term stands for the increased rent for types in $\left[\theta_{0}\left(\theta^{*}\right), \theta^{*}\right]$ from the necessary increase in the skin of the game. Because public funds are costly $(\lambda>0)$, this increase in rent represents a social cost. And so, at the optimum $\theta^{*}>\theta_{0}\left(\theta^{*}\right)$.

The next proposition characterizes the upper bound on social welfare, that is, in view of the following, implementability proposition, the optimal intervention.

Proposition 7. (comparative statics). The optimal intervention: 
(i) involves full financing $\left(\theta^{*}=1\right)$ if $\lambda \leq \lambda_{1}^{\prime}$ for some $\lambda_{1}^{\prime}>0$, financing for types $\theta \leq \theta^{*}$ where $\theta^{*}$ solves $d \bar{W} / d \theta^{*}=0$ for $\lambda_{1}^{\prime} \leq \lambda \leq \lambda_{2}^{\prime}$, and no intervention if $\lambda \geq \lambda_{2}^{\prime}$;

(ii) unless there is no financing, always involves a region with a clean-up of the balance sheet/buybacks $(U(\theta)=B)$ and a region in which the seller keeps some skin in the game $\left(\theta_{0}\left(\theta^{*}\right)<\theta^{*}\right)$;

(iii) is more extensive ( $\theta^{*}$ increases), the lower the cost of public funds $(\lambda)$, and the higher the social value of the new project $(S)$;

(iv) is more extensive than under buybacks.

That rescues are more extensive than under buybacks is natural: The possibility of asking the seller to keep some skin in the game alleviates adverse selection and makes the intervention less costly.

\section{Implementation}

Let us next note that the optimal intervention can always take the form of a cleaning-up of the worst types followed by refinancing of (some of) the remaining ones by the market. Furthermore, and as illustrated in Figure 4, the intervention cannot be non-comprehensive (i.e., does not cover all types in $\left.\left[0, \theta^{*}\right]\right)$. The reason for this is that the market, if confronted with a population $\left[\theta^{*}, 1\right]$ would in general want to finance at least a fraction of these types. Anticipating this, types in $\left[0, \theta^{*}\right]$ would refrain from joining the government's scheme.

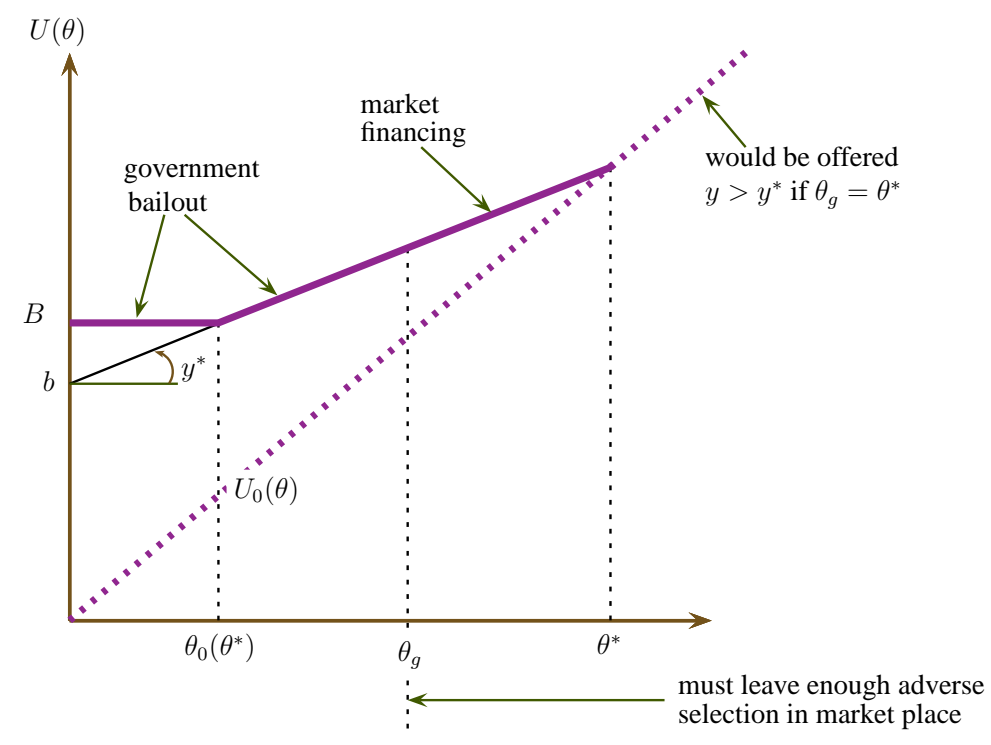

Figure 4: leaving enough adverse selection in the marketplace 
Proposition 8. : The optimal intervention is not comprehensive (the government does not attract all types in $\left.\left[0, \theta^{*}\right]\right)$. The upper bound on social welfare characterized in Proposition 7 can be implemented by an intervention that attracts types in $\left[0, \theta_{g}\right]$ for some $\theta_{g}$ and leaves types in $\left[\theta_{g}, 1\right]$ to the market, where $\theta_{g}$ is uniquely defined by:

$$
\int_{\theta_{g}}^{\theta^{*}}\left[\theta R_{0}+S-V\left(\theta y^{*}\right)\right] d F(\theta)=0 .
$$

Proof: Let $\Pi_{m}\left(\theta_{g}, \theta^{*}\right) \equiv \int_{\theta_{g}}^{\theta^{*}}\left[\theta R_{0}+S-V\left(\theta y^{*}\right)\right] d F(\theta)$. Note first that $\theta^{*} \geq \theta_{m}^{*}$ and so $\Pi_{m}\left(0, \theta^{*}\right) \leq 0$. Second, $\Pi_{m}\left(\theta_{g}, \theta^{*}\right)>0$ for $\theta_{g}$ close to $\theta^{*}$, since $\theta^{*} R_{0}+S-V\left(\theta^{*} y^{*}\right)=$ $\theta^{*} R_{0}+S-U_{0}\left(\theta^{*}\right)=S>0$. Thus there exists a (unique) solution to (8).

Suppose that $\theta_{g}>\theta_{0}\left(\theta^{*}\right)$ (where $b+y^{*} \theta_{0}\left(\theta^{*}\right)=B$ : see Figure 4). Then by giving two incentive schemes $\left\{z=\varepsilon, y=y^{*}-\eta\right\}$ such that $\varepsilon=\theta_{g} \eta$ and $\{z=B-b+\kappa, y=0\}$, the government attracts types $\left[0, \theta_{g}\right]$ and only those types. When $\varepsilon, \eta$ and $\kappa$ converge to 0 , the solution converges to the optimum. Thus, the optimum can be approximated through a scheme yielding a unique continuation equilibrium. One gets exact implementation for $\varepsilon=\eta=\kappa=0$, but then the equilibrium set of types accepting the government offer is not necessarily $\left[0, \theta_{g}\right]$; the allocation however is unique. ${ }^{33}$ Finally, when $\theta_{g} \leq \theta_{0}\left(\theta^{*}\right)$, then the equilibrium allocation is again unique.

Cost of interventions. One might conjecture that interventions should be reasonably cheap as sellers are eager to be financed and so are willing to part with their legacy asset at a low price. This high willingness to sell, though, is already accounted for by the market. In fact, the government at the optimum policy always (and not only on average) overpays for the legacy asset or the stake: From (8) and the fact that profit is increasing in $\theta$ (Lemma 4(ii)),

$$
\pi(\theta)<0 \text { for all } \theta \in \Theta_{g}
$$

Ex ante moral hazard. As in the case of buybacks, we can add a stage, stage 0 , at which the seller chooses the distribution $F(\theta \mid e)$ at increasing and convex cost $\psi(e)$. The effort increases the distribution in the sense of first-order stochastic dominance. The equilibrium utility $U\left(\theta, e^{*}\right)$

\footnotetext{
${ }^{33}$ If $y_{m}<y_{g}$, then all types in $\left[0, \theta^{*}\right]$ join the government scheme and so $y_{m}>y_{g}$, a contradiction. If $y_{m}>y_{g}$, no type joins the government scheme (from robust choice), and so the intervention has no effect.
} 
is given by the socially optimal rent for distribution $F\left(\theta \mid e^{*}\right)$ corresponding to the equilibrium effort $e^{*}$. The expectation of intervention always creates moral hazard: ${ }^{34}$

Proposition 9. : Suppose that the market breaks down in the absence of intervention and that the optimal government policy is not laissez-faire. The equilibrium effort is smaller under a government intervention than under laissez-faire.

Proof: Under an intervention the seller chooses her effort $e$ so as to maximize:

$$
\int_{0}^{1} U\left(\theta, e^{*}\right) d F(\theta \mid e)-\Psi(e)=B+\int_{0}^{1} \dot{U}\left(\theta, e^{*}\right)[1-F(\theta \mid e)] d \theta-\Psi(e),
$$

while the laissez-faire effort is given by the maximization of

$$
\int_{0}^{1} \dot{U}_{0}(\theta)[1-F(\theta \mid e)] d \theta-\Psi(e)
$$

But $\dot{U}\left(\theta, e^{*}\right) \in\left\{0, y, \dot{U}_{0}(\theta)\right\}$ where $\dot{U}_{0}(\theta)>y$. By supermodularity, the optimal effort under laissez-faire is higher than under intervention.

\section{Adding a cost of government intervention}

Interventions by the government involve multiple costs: administrative costs and political backlash (increasing with the size of the intervention) for the government, political constraints (cap on bonuses, ...) and stigma of participation for the rescued entity. We do not attempt to embody all these potential costs into the analysis. Rather, we content ourselves with the following exercise: Suppose that the government incurs an arbitrarily small per unit cost, $\varepsilon[f(\theta) d \theta]$, of rescuing types in $[\theta, \theta+d \theta]$; what is the optimal pattern of intervention?

Proposition 10. As the unit cost of intervention $\varepsilon$ converges to 0 , the optimal intervention converges to the one characterized in Proposition 7. Furthermore, there is a unique implementation outcome: There exists $\theta_{g}$ (given by (A.2 )) such that

$\checkmark$ types $\theta<\theta_{g}$ are rescued by the government,

\footnotetext{
${ }^{34}$ We here assume that the government cannot commit. Were the government able to commit to a rent schedule $\{U(\cdot)\}$ before the choice of effort, the optimal intervention would also need to account for the impact of intervention on the choice of effort. While deriving the optimality conditions for the commitment case is straightforward, specific results depend on what part of the distribution $F$ marginal effort impacts most.
} 
$\checkmark$ types $\theta$ in $\left[\theta_{g}, \theta^{*}\right]$ are refinanced by the market.

Intuitively, the size of the free market is maximized if the government rescues the worst types: this leaves more profitable types to, and therefore expands the market.

\section{Discussion}

Other causes of freezing. We have derived the implications of a common factor of market dryup, adverse selection. The widespread focus on toxic assets, lack of confidence about the quality of these assets, counterparty risk and losses associated with inaccurate ratings all suggest that accurate information is not widely available prior to bailouts. But market freezes are reinforced by other factors, such as some ${ }^{35}$ regulated banks' strategies to avoid recognizing losses and having to raise more capital, the shortage of financial muscle ${ }^{36}$ heterogenous beliefs or ambiguity aversion. ${ }^{37}$. The nature of optimal interventions, if any, depends on the freeze's proximate cause. Consider, for example, a regulated entity subject to a capital adequacy requirement and owning an illiquid legacy asset subject to, and overvalued by historical cost accounting. Either potential buyers don't know the value of the asset and the adverse selection issues studied in this paper are relevant. Or they do, and then the optimal intervention, if any, consists in auctioning off the asset on the market (de facto imposing fair value accounting), together with liquidity support (of $\left[B-S-\theta R_{0}\right]$ in our model). If there is a very limited set of potential buyers and so the government is worried about collusion (a sale at a favorable price so as to boost government subsidies), then the analysis resembles that of adverse selection developed in this paper.

Asset fungibility. Our basic model resembles Myers-Majluf (1984)'s, except that, to be able to discuss buyouts, we assumed that the legacy asset and the new project can be separated (are non-fungible). Let us briefly discuss the implications of fungibility; to remain in the spirit of Myers-Majluf, assume that $R_{0}=R_{1}$, so in case only one activity succeeds, investors cannot

\footnotetext{
${ }^{35}$ Douglas Diamond and Raghuram Rajan (2010) point out that in the recent crisis a number of regulated institutions had excess book capital.

${ }^{36}$ There is now a large literature, starting with Franklin Allen and Douglas Gale (1994), on the idea that prospective buyers able to manage the asset are in limited number and may not have enough capital to purchase the asset. Allen and Elena Carletti (2008) make a case for the role of cash-in-the-market pricing in the freezing of the securitized asset markets.

${ }^{37}$ Ricardo J. Caballero and Arvind Krishnamurthy (2008).
} 
know whether it is the legacy asset or the new project. An incentive scheme then specifies a fixed transfer, and rewards for one or two successes. Letting $y(\theta)$ denote the reward for two successes, $t(\theta)$ the reward for one success (conditional on the new project being financed), and $t$ and $y$ denote the highest such values, then

$$
U(\theta) \geq \max \left\{B+\theta t, b+\theta y, U_{0}(\theta)\right\}
$$

The constrained-efficient allocation is slightly different from the one under non-fungibility. For example, if $\theta=0$ is to be financed and to not shirk, $t \geq B-b$, and so for all $\theta, U(\theta) \geq$ $B+\theta(B-b):$ the initial flat part of the constrained optimum is now positively sloped.

Adverse selection on new project as well. We have not allowed for private information about the new project. The analysis of two-dimensional screening is likely to be complex. However the insights can be seen to extend to the special case of perfect correlation between the legacy asset and the new project (so adverse selection is de facto single-dimensional). We briefly explain why in the case of buybacks. Suppose, first, that none of the surplus is pledgeable (so $B(\theta)=S(\theta)+I$ ); the financing condition is then $p \geq I$. Assuming that $d S / d \theta<R_{0}$, there exists a unique cutoff $\theta^{*}$ such that $\theta^{*} R_{0}=p+S\left(\theta^{*}\right)$, and so the analysis of Section II. carries through. Second, suppose that some of the surplus is pledgeable, but the new project succeeds when and only when the legacy project does, while $b$ and $B$ are known. In particular $S(\theta)=\theta R_{2}+b-I$ for some $R_{2}$. Again, the analysis is basically unchanged.

\section{Conclusion}

The introduction already summarized the main insights. Let us discuss some other applications and alleys for future research.

Other public-sector applications. The idea that participants in a scheme have an eye on the subsequent free market has other applications. Sellers are reluctant to show up at the discount window and countries have shunned the IMF's CCL (contingent credit line) mechanism by fear of the stigma associated with participation in those schemes, or, equivalently, in search of the positive signal sent by non-participation. ${ }^{38}$

\footnotetext{
${ }^{38}$ Signaling occurs also at the stage of exit, and not only of entry. A case in point is the rush by Goldman, JP
} 
Private-sector principals and market tainting strategies. Mechanism-dependent participation constraints also naturally arise in industrial organization, as when a dominant firm with market power designs a non-linear tariff, knowing that a competitive fringe of rivals will react with their own policies. Situations in which a dominant operator moves first in a market marred by adverse selection include market segmentation by a manufacturer or the selection of a clientele (through pricing and conditions) by a venture capitalist, investment bank or rating agency. Like in this paper, a high-rent policy inside the scheme raises the agent's outside option through a selection effect. The essential difference, though, is that the principal would strictly gain from the absence of a market: While the market delivers too small an agent's rent in my framework, it delivers (from the point of view of the principal) too high a rent in the market tainting application. By focusing on simultaneous offers, the competitive screening literature has ignored the mechanism-dependent participation constraint problem. This is an important alley for future research.

Contracting with externalities. Contracts often exert externalities on parties not involved in the contract (see Ilya Segal (1999)'s classic survey). “Contracting with externalities” is usually studied in symmetric information contexts, or ones in which externalities are independent of private information. But it is easy to envision situations in which exactly what types turn down contract offers affects one's willingness to contract: In general, who tenders the shares, and not only how many shares are tendered, matters for the post-takeover outcome if monitoring or dissonance are relevant. In a non-excludable public good model, an agent's outside option may depend on who agrees to contribute to the public good if some unverifiable effort or contract incompleteness prevent an accurate ex-ante specification of contributions. The payoff to belonging to or staying out of a cartel depends on privately-known marginal costs. ${ }^{39}$ In these examples, and many others, participation constraints are endogenous.

Limited commitment. We have assumed that the government can commit to a rescue scheme. If the government cannot commit not to renegotiate, the sellers will adopt a lower take-up rate and some will wait for a better offer later on. The protracted recapitalization of

Morgan and other institutions to reimburse loans granted by US authorities, although this may also be explained by the reluctance of managers to confront government interference.

${ }^{39}$ The first example was suggested by Segal and Michael Whinston, the other two by Sandeep Baliga. 
Japanese banks is an interesting case in point (Hoshi-Kashyap 2010). This situation, in the absence of a market, has been studied in the literature, ${ }^{40}$ and has been shown to lead to a slower revelation of information and equilibrium delays. The novelty here is that a market can open over time. The interaction between renewed government offers and market opening is an exciting topic for future research.

Multi-sector analysis. Another limit to government intervention is that it may indirectly benefit sectors which the government does not intend to rescue or just help. For example, the government might want to rescue banks because they have small depositors or because they are central to the credit and payment systems. But it may not want to commit taxpayer money to the benefit of hedge funds. Yet if assets can be traded between hedge funds and banks, banks are willing to purchase dubious assets (assets they don't know the value of) from hedge funds if they anticipate that a government's asset repurchase scheme will be set up. ${ }^{41}$ If this arbitrage does not discourage the government from intervening, the government may then subsidize hedge funds or banks without need for cash or both.

These and other exciting research alleys related to mechanisms with endogenous participation constraints are left for future research.

\footnotetext{
${ }^{40}$ E.g., Mathias Dewatripont (1989), Laffont-Tirole (1990) and Oliver Hart and Tirole (1988).

${ }^{41}$ Interestingly, Zhiguo He, In Gu Khang, and Krishnamurthy (2010) document that hedge funds and brokerdealers in 2008 sold assets to commercial banks, so those assets benefited from the government's debt guarantees.
} 


\section{References}

Aghion, Philippe, Patrick Bolton, and Steven Fries. 1999. "Optimal Design of Bank Bailouts: The Case of Transition Economies.” Journal of Institutional and Theoretical Economics, 155: $51-70$.

Aghion, Philippe, Patrick Bolton, and Jean Tirole. 2004. "Exit Options in Corporate Finance: Liquidity versus Incentives." Review of Finance, 8(3): 327-353.

Akerlof, George. 1970. "The Market for Lemons, Qualitative Uncertainty and the Market Mechanism." Quarterly Journal of Economics, 84(3): 488-500.

Allen, Franklin, and Elena Carletti. 2008. “The Role of Liquidity in Financial Crises.” Jackson Hole Conference Proceedings, Federal Reserve Bank of Kansas City, 379-412.

Allen, Franklin and Douglas Gale. 1994. Financial Innovation and Risk Sharing. Cambridge: MIT Press.

An, Mark Yuying. 1998. "Logconcavity versus Logconvexity: A Complete Characterization.” Journal of Economic Theory, 80(2): 350-369.

Armstrong, Mark and John Vickers. 2001. “Competitive Price Discrimination.” Rand Journal of Economics, 32(4): 579-605.

Armstrong, Mark and John Vickers. 2010. "Competitive Nonlinear Pricing and Bundling." Review of Economic Studies, 77(1): 30-60.

Attar, Andrea, Thomas Mariotti, and François Salanié. 2009. "Non-Exclusive Competition in the Market for Lemons." http://idei.fr/vitae.php?i=118

Bénabou, Roland and Jean Tirole. 2006. "Incentives and Prosocial Behavior." American Economic Review, 96(5): 1652-1678.

Biais, Bruno and Thomas Mariotti. 2005. "Strategic Liquidity Supply and Security Design." Review of Economic Studies, 72(3): 615-649. 
Biais, Bruno, David Martimort, and Jean-Charles Rochet. 2000. "Competing Mechanisms in a Common Value Environment.” Econometrica, 68(4): 799-837

Bolton, Patrick, Tano Santos, and Jose Scheinkman. 2009. "Outside and Inside Liquidity." Forthcoming. Quarterly Journal of Economics.

Caballero, Ricardo J., and Arvind Krisnamurthy. 2008. "Collective Risk Management in a Flight to Quality Episode.” Journal of Finance, 63(5): 2195-2230.

Calzolari, Giacomo, and Alessandro Pavan. 2006. "On the Optimality of Privacy in Sequential Contracting." Journal of Economic Theory, 130(1): 168-204.

Coase, Ronald H. 1972. "Durability and Monopoly." Journal of Law and Economics, 15(1): $143-149$.

Dewatripont, Mathias. 1989. "Renegotiation and Information Revelation over Time: The Case of Optimal Labor Contracts." Quarterly Journal of Economics, 104(3): 589-620.

Diamond, Douglas and Raghuram Rajan. 2010. Forthcoming. "Fear of Fire Sales, Illiquidity Seeking, and the Credit Freeze." Quarterly Journal of Economics.

Faure-Grimaud, Antoine. 1997. "The Regulation of Predatory Firms.” Journal of Economics and Management Strategy, 6(4): 849-876.

Faure-Grimaud, Antoine. 2002. “Using Stock Price Information to Regulate Firms.” Review of Economic Studies, 69(1): 169-190.

Faure-Grimaud, Antoine and Denis Gromb. 2004. "Public Trading and Private Incentives." Review of Financial Studies, 17(4): 985-1014.

Fudenberg, Drew and Jean Tirole. 1991. Game Theory. MIT Press.

Haile, Philip A. 2003. “Auctions with Private Uncertainty and Resale Opportunities.” Journal of Economic Theory, 108(1): 72-110. 
Hart, Oliver D. and Jean Tirole. 1988. "Contract Renegotiation and Coasian Dynamics." Review of Economic Studies, 55(4): 509-40.

He, Zhiguo, Khang, In Gu, and Arvind Krishnamurthy. 2010. "Balance Sheet Adjustments during the 2008 Crisis."

http://www.kellogg.northwestern.edu/Faculty/Directory/

Krishnamurthy_Arvind.aspx\#research

Heider, Florian, Marie Hoerova, and Cornelia Holthausen. 2010. "Liquidity Hoarding and Interbank Market Spreads: The Role of Counterparty Risk. http://ssrn.com/ abstract $=1362113$

Hellwig, Martin. 1987. "Some Recent Developments in the Theory of Competition in Markets with Adverse Selection.” European Econonomic Review, 31: 319-325.

Hendel, Igal and Alessandro Lizzeri. 1999. "Adverse Selection in Durable Goods Markets." American Economic Review, 89(5): 1097-1115.

Hendel, Igal and Alessandro Lizzeri. (2002) “The Role of Leasing under Adverse Selection.” Journal of Political Economy, 110(1): 113-143.

Hirshleifer, Jack. 1971. "The Private and Social Value of Information and the Reward to Inventive Activity." American Economic Review, 61(4): 561-574.

Hoshi, Takeo and Anil Kashyap. 2010. "Will the U.S. Bank Recapitalization Succeed? Eight Lessons from Japan.” Journal of Financial Economics, 97(3): 398-417.

Jéhiel, Philippe and Benny Moldovanu. 1996. "Strategic Non Participation.” Rand Journal of Economics, 27(1): 84-98.

Katz, Michael and Carl Shapiro. 1986. "Technology Adoption in the Presence of Network Externalities." Journal of Political Economy, 94: 822-841.

Kurlat, Pablo. 2010. "Lemons, Market Shutdowns and Learning." http: / / econ-www . mit.edu/grad/pkurlat/research 
Laffont Jean-Jacques and Jean Tirole. 1990. "Adverse Selection and Renegotiation in Procurement." Review of Economic Studies, 57(4): 597-626.

Landier, Augustin and Kenichi Ueda. 2009. "The Economics of Bank Restructuring: Understanding the Options." IMF STPN, ${ }^{\circ} 12: 39$ pages.

Lizzeri, Alessandro. 1999. "Information Revelation and Certification Intermediaries." Rand Journal of Economics, 30: 214-232.

Malherbe, Frédéric. 2011. "Self-Fulfilling Liquidity Dry-Ups."

http://homepages.ulb.ac.be/ fmalherb/

Maskin, Eric S. and Jean Tirole. 1992. "The Principal Agent Relationship with an Informed Principal, II: Common Values.” Econometrica, 60(1): 1-42.

Milgrom, Paul and Nancy Stokey. 1982. "Information, Trade and Common Knowledge.” Journal of Economic Theory, 26(1): 177-227.

Minelli, Enrico, and Salvatore Modica. 2009. "Credit Market Failures and Policy," Journal of Public Economic Theory, 11(3): 363-382.

Myers, Stewart C. and Nicholas S. Majluf. 1984. "Corporate Financing and Investment Decisions When Firms Have Information that Investors Do Not Have.” Journal of Financial Economics, 13(2): 187-221.

Pesendorfer, Wolfgang. 1995. "Design Innovation and Fashion Cycles.” American Economic Review, 85(4): 771-792.

Philippon, Thomas and Philipp Schnabl. 2009. “Efficient Recapitalization.” NBER WP 14929. Philippon, Thomas and Vasiliki Skreta. 2010. "Optimal Interventions in Markets with Adverse Selection.” NBER WP 15785.

Rochet, Jean-Charles and Lars Stole. 2002. "Nonlinear Pricing with Random Participation.” Review of Economic Studies, 69(1): 277-311. 
Rockafellar, R. Tyrrell. 1970. Convex Analysis. Princeton University Press.

Rothschild, Michael and Joseph Stiglitz. 1976. "Equilibrium in Competitive Insurance markets: An Essay in the Economics of Imperfect Information.” Quarterly Journal of Economics, 90(4): 629-650.

Segal, Ilya R. 1999. "Contracting with Externalities.” Quarterly Journal of Economics, 114 (2): 337-388.

Zheng, Charles Zhoucheng. 2002. "Optimal Auction with Resale.” Econometrica, 70(6): $2197-2224$. 
Overcoming Adverse Selection: How Public Intervention Can Restore Market

\section{Functioning}

\section{APPENDIX}

\section{Suboptimality of trivial interventions under buybacks}

Suppose that $p_{g}<B-S$ and so the seller will not be able to finance the new project if she joins the governmental scheme. Let us first look for a pure strategy equilibrium. Either $p_{m}<B-S$ and then there is no private market as there are no gains from trade. Or $p_{m}>B-S$ and then no-one joins the governmental scheme.

Let $\theta$ denote the lowest value of $\theta_{g}$ such that the market can be revived when types $\theta \leq \theta_{g}$ accept the government's offer: ${ }^{\dagger}$

$$
\theta=\begin{aligned}
& B \\
& R_{0}
\end{aligned}
$$

Let $\theta^{* *}\left(p_{g}\right)$ be defined by:

$$
U_{0}\left(\theta^{* *}\left(p_{g}\right)\right)=p_{g}
$$

If $\theta^{* *}\left(p_{g}\right)<\theta$, the equilibrium involves no rejuvenation. Welfare is then

$$
\begin{aligned}
W & =p_{g} F\left(\theta^{* *}\left(p_{g}\right)\right)+\int_{\theta^{* *}\left(p_{g}\right)}^{1} U_{0}(\theta) d F(\theta)-(1+\lambda)\left[p_{g}-m^{-}\left(\theta^{* *}\left(p_{g}\right)\right) R_{0}\right] F\left(\theta^{* *}\left(p_{g}\right)\right) \\
& <E\left[U_{0}(\theta) d F(\theta)\right]
\end{aligned}
$$

unless $p_{g}=0$. Offering such a $p_{g}$ necessarily reduces welfare.

Assume next that $\theta^{* *}\left(p_{g}\right) \geq \theta$. Then if $\theta_{g}=\theta^{* *}\left(p_{g}\right), p_{m}+S \geq B$ and so $p_{m}>p_{g}$, a contradiction since no-one would join the government's scheme.

${ }^{\dagger}$ An offer at price $p$ that revives the market $(p \geq B-S)$ yields net profit

$$
\left[\int_{\theta_{g}}^{\frac{p-S}{R_{0}}} \theta d F(\theta)\right] R_{0}-\left[F\left(\frac{p-S}{R_{0}}\right)-F\left(\theta_{g}\right)\right] p,
$$

whose derivative with respect to $p$ is negative. Hence, a necessary and sufficient condition for market rebound is that at $p=\theta_{g} R_{0}-S, p \geq B-S$ or $\theta_{g} R_{0} \geq B$. 
So necessarily $\theta_{g}=\underline{\theta}$ and financing by the market must be random. When refusing to join the government's scheme, the seller is financed by the market at price $p_{m}=B-S$ with probability $\alpha$ and the market breaks down with probability $1-\alpha$ such that

$$
p_{g}=(1-\alpha) U_{0}\left(\theta_{g}\right)+\alpha B
$$

Finally,

$$
p_{m}=R_{0} H\left(\theta_{g}, \frac{p_{m}+S}{R_{0}}\right) \Longleftrightarrow B-S=R_{0} H\left(\theta_{g}, \frac{B}{R_{0}}\right)
$$

Welfare is

$$
\begin{aligned}
W= & p_{g} F\left(\theta_{g}\right)-(1+\lambda) \int_{0}^{\theta_{g}}\left[p_{g}-\theta R_{0}\right] d F(\theta) \\
& +\alpha\left[\int_{\theta_{g}}^{\theta^{*}}\left(p_{m}+S\right) d F(\theta)+\int_{\theta^{*}}^{1} U_{0}(\theta) d F(\theta)\right] \\
& +(1-\alpha)\left[\int_{\theta_{g}}^{1} U_{0}(\theta) d F(\theta)\right]
\end{aligned}
$$

$W$ is linear in $\alpha$ ( $p_{g}$ is a function of $\alpha$, whereas all the other variables are being held constant as $\alpha$ varies). If $W$ decreases with $\alpha$, then it is bounded above by

$$
p_{g} F\left(\theta_{g}\right)-(1+\lambda) \int_{0}^{\theta_{g}}\left[p_{g}-\theta R_{0}\right] d F(\theta)+\int_{\theta_{g}}^{1} U_{0}(\theta) d F(\theta)
$$

which is lower than the laissez-faire welfare $\int_{0}^{1} U_{0}(\theta) d F(\theta)$.

If $W$ increases with $\alpha$, the maximum is achieved at $\alpha=1$. The intervention then coincides with the minimum non-trivial intervention, except that there is no investment for types below $\theta_{g}$; hence this intervention is dominated by doing the minimal non-trivial intervention and investing for all participating sellers.

\section{Ex-ante moral hazard under buybacks}

Let us extend the model by introducing a "stage 0", at which the seller chooses the asset quality. At private and unobserved cost $\Psi(e)$, the seller generates distribution $F(\theta \mid e)$ such that $\partial(f / F) / \partial e>0$ and $\partial(f / F) / \partial \theta<0$. 


\section{Proposition 11.}

(i) Strategic substitutability. Consider an arbitrary (i.e., possibly out of equilibrium) expectation $e^{*}$. Under ex-ante moral hazard, the seller chooses a higher effort (e) when expected to choose a lower one $\left(e^{*}\right)$.

(ii) Consequently, there exists a unique equilibrium.

(iii) If there is an equilibrium intervention, effort is lower than in the absence of intervention.

Intuitively, if the equilibrium effort is high, interventions face less adverse selection and are more generous (higher $p$ ). This implies that the seller expects to be bailed out more often and so puts in less effort.

Proof: (i) For conciseness let us restrict our attention to the region of parameters for which an interior solution prevails:

$$
\frac{f\left(\theta^{*} \mid e^{*}\right)}{F\left(\theta^{*} \mid e^{*}\right)}=\frac{\lambda R_{0}}{(1+\lambda) S}
$$

Condition (A.1 ) defines a policy cutoff $\theta^{*}\left(e^{*}\right)$ as a function of the equilibrium value of effort. From $\partial(f \mid F) / \partial e>0, \theta^{*}$ is an increasing function of $e^{*}$.

The seller chooses her effort $e$ so as to maximize:

$$
\mathcal{U} \equiv U_{0}\left(\theta^{*}\left(e^{*}\right)\right) F\left(\theta^{*}\left(e^{*}\right) \mid e\right)+\int_{\theta^{*}\left(e^{*}\right)}^{1} U_{0}(\theta) d F(\theta \mid e)-\Psi(e)
$$

or, after an integration by parts

$$
\mathcal{U}=U_{0}(1)-\int_{\theta^{*}\left(e^{*}\right)}^{1} R_{0} F(\theta \mid e) d \theta-\Psi(e) .
$$

And so

$$
\frac{\partial^{2} \mathcal{U}}{\partial e^{*} \partial e}=R_{0} \frac{d \theta^{*}}{d e^{*}} F_{e}\left(\theta^{*}\left(e^{*}\right) \mid e\right)<0
$$

(ii) Uniqueness of equilibrium, if it exists, is a corollary of (i). Consider $e=R\left(e^{*}\right)$ given by $\Psi^{\prime}(e)=R_{0} \int_{\theta^{*}\left(e^{*}\right)}^{1}\left[-F_{e}(\theta \mid e)\right] d \theta$. The equilibrium may involve mixed strategies by the government if at the level $\widehat{e}$ at which the government is indifferent between an intervention and 
laissez-faire, $R(\widehat{e})<\widehat{e}$. The equilibrium then has $\bar{e}=\widehat{e}$ and randomization by the government between intervention and laissez-faire.

(iii) Under laissez-faire the first-order condition is

$$
\Psi^{\prime}(e)=R_{0} \int_{0}^{1}\left[-F_{e}(\theta \mid e)\right] d \theta
$$

Commitment. Let us now assume that the government can commit to a price $p_{g}$ (and therefore to a cutoff $\theta^{*}$ ) before effort is chosen. Effort is then chosen so as to maximize

$$
\theta^{*} R_{0} F\left(\theta^{*} \mid e\right)+\int_{\theta^{*}}^{1} \theta R_{0} d F(\theta \mid e)-\psi(e)
$$

The cross-partial derivative of this function with respect to $\theta^{*}$ and $e$ is $R_{0} F_{e}\left(\theta^{*} \mid e\right)<0$. So a lower $\theta^{*}$ induces a higher effort. In turn, the government wants to commit to a price that is lower than that that will prevail under non-commitment.

\section{Proof of Proposition 6}

Consider the upper envelope of the equilibrium utilities offered by the buyers:

$$
U(\theta)=\sup \left\{U_{i}(\theta)\right\}
$$

As earlier, let

$$
y=\sup _{\left\{i, \theta \mid x_{i}(\theta)=1\right\}}\left\{y_{i}(\theta)\right\} \text { and } \tilde{\theta} \equiv \sup _{\{\theta, i\}}\left\{\theta \mid x_{i}(\theta)=1\right\}
$$

From the proof of Lemma 2, there exists $\stackrel{v}{y} \geq y$, with strict inequality if and only if $z(\widetilde{\theta}) \equiv$ $z>0$, such that an upper bound on buyer profit is

$$
\int_{0}^{v}\left[\theta R_{0}+S-V(\theta \mathrm{v})\right] d F_{m}(\theta)
$$

which, from the definition of the constrained efficient outcome, is strictly negative if $\stackrel{v}{y}>y_{m}$. If $\stackrel{v}{y}=y_{m}$, then (a) $z=0$ (and so $\stackrel{v}{y}=y$ ) and (b) $x(\theta)$ cannot be equal to 0 on a positive-measure subset of $[0, \stackrel{v}{\theta}]$, otherwise the buyers would make a strictly negative profit. The outcome then coincides with the constrained efficient outcome. 
So let us assume that $\stackrel{v}{y}<y_{m}$ and so, a fortiori, $y<y_{m}$. Because $x(\theta)=0$ for $\theta \in\left[\widetilde{\theta}, \theta^{*}\right]$, the profit made by buyers on those types is strictly negative. Furthermore, it must be the case that $\theta R_{0}+S-U(\theta)>0$ on an interval $[\widetilde{\theta}-\varepsilon, \widetilde{\theta}]$ for some $\varepsilon>0 .^{\ddagger}$

Suppose first that $z>0$ and consider an "entering buyer" (by this we mean a buyer with a zero or arbitrarily small equilibrium profit, as we will show that the proposed contract makes a strictly positive profit) offering a single skin-in-the-game contract specifying $\{z-\kappa, y+\eta, x=$ $1\}^{\S}$ defining a schedule $\widehat{U}(\theta)=\max \left\{B, z-\kappa+(y+\eta) \theta+b, U_{0}(\theta)\right\}$, such that $\eta>0$ and

$$
U(\widetilde{\theta}-\varepsilon)=z-\kappa+b+(y+\eta)(\widetilde{\theta}-\varepsilon) .
$$

The buyer then attracts at least types in $[\widetilde{\theta}-\varepsilon, \widetilde{\theta}]$, which by continuity yields a strictly positive profit for $(\varepsilon, \eta, \kappa)$ small. He may also attract types in $\left[\widetilde{\theta}, \theta^{*}\right]$, which a fortiori are profitable. He does not attract any type below $\widetilde{\theta}-\varepsilon$. Hence the deviation is strictly profitable.

Suppose finally that $z=0$. Let the deviating buyer make a single skin-in-the-game offer $\{0, y+\eta, x=1\}$. From robust choice this schedule attracts exactly types in $\left[\theta^{* *}, \theta^{*}\right]$ with $\theta^{* *}<\widetilde{\theta}$, as well as some (profitable) types above $\theta^{*}$. But even if $\theta^{* *}=0$, this deviation is strictly profitable since $y+\eta<y_{m}$ for $\eta$ small.

\section{Proof of Proposition 7}

Only (iv) and (v) require some elaboration.

(iv) Note that

$$
\operatorname{sign}\left(\frac{d \bar{W}}{d \theta^{*}}\right)=\operatorname{sign}\left[\frac{(1+\lambda) S}{\lambda b}-\int_{\theta_{0}\left(\theta^{*}\right)}^{\theta^{*}} \frac{\theta}{\left(\theta^{*}\right)^{2}} \frac{f(\theta)}{f\left(\theta^{*}\right)} d \theta\right]
$$

Under good news about the prior distribution, $f(\theta) / f\left(\theta^{*}\right)$ decreases and so $\partial W / \partial \theta^{*}$ is positive over a wider range of $\theta^{*} \mathrm{~s}$.

(v) Recall the first-order condition under pure buybacks:

$$
f\left(\theta^{*}\right)(1+\lambda) S=F\left(\theta^{*}\right) \lambda\left(R_{0}+\lambda S\right)
$$

\footnotetext{
${ }^{\ddagger}$ Recall that by convexity of $U(\cdot): \frac{d}{d \theta}\left(\theta R_{0}+S-U(\theta)\right) \geq R_{0}-y>0$.

Furthermore, $\pi(\theta) \leq \theta R_{0}+S-U(\theta)$; so if $\theta R_{0}+S-U(\widetilde{\theta}) \leq 0$, the buyers' profit is strictly negative.

$\S$ It is also possible to upset the equilibrium through a contract specifying the same $z$.
} 
To show that $\theta^{*}$ is higher under a general scheme, we note that

$$
F\left(\theta^{*}\right)>\int_{\theta_{0}\left(\theta^{*}\right)}^{\theta^{*}} \frac{\theta b}{\left(\theta^{*}\right)^{2}} f(\theta) d \theta .
$$

Indeed, the right-hand side of this inequality is bounded above by $\int_{0}^{\theta^{*}} \frac{\theta b}{\left(\theta^{*}\right)^{2}} f(\theta) d \theta=$ $b m^{-}\left(\theta^{*}\right) F\left(\theta^{*}\right) /\left(\theta^{*}\right)^{2}$. Thus, we need to show that at the optimum of the outright sales mechanism:

$$
\frac{\theta^{*} R_{0}}{b}>\frac{m^{-}\left(\theta^{*}\right)}{\theta^{*}}
$$

The LHS of this inequality exceeds 1 since $\theta^{*} R_{0}=b+\theta^{*} y$. The RHS is always smaller than 1.

\section{Proof of Proposition 10}

Let $\xi_{g}(\theta)=1$ if $\theta \in \Theta_{g}$ and $\xi_{g}(0)=0$ otherwise. Let

$$
m_{g}=\int_{0}^{1} \xi_{g}(\theta) d F(\theta)
$$

denote the size of government involvement. Welfare can now be rewritten as

$$
\widehat{W} \equiv W-\varepsilon m_{g}=E[S x(\theta)]+\lambda E[\pi(\theta)]-\varepsilon m_{g}+\bar{\theta} R_{0}
$$

where $\pi(\theta)$ is the monetary outcome on type $\theta\left(\pi(\theta)+U(\theta)=\theta R_{0}+S x(\theta)\right)$. The maximization of (A.2 ) subject to the (IC) constraint and

$$
E\left[\left[1-\xi_{g}(\theta)\right] \pi(\theta)\right] \geq 0
$$

is a priori complex.

But consider any possible intervention and corresponding $\Theta_{g}$ and $\Theta_{m}$. Let $\{x(\cdot), U(\cdot)\}$ be the combined (government plus market) mechanism faced by the seller. Consider having the government deviate to offer the same mechanism $\{x(\cdot), U(\cdot)\}$ and asking precisely the types in $\Theta_{g}$ to participate in the government's scheme. This is incentive-compatible and produces exactly the same welfare and intervention costs as before. So without loss of generality we can 
restrict attention to strategy profiles where the government offers the same mechanism as the market (but attracts only a subset of types). So, letting $\widetilde{\pi}(\theta) \equiv \theta R_{0}+S-V(\theta y)$ where $y$ is the skin in the game offered by the market. We can now without loss of generality solve:

$$
\underset{\left\{\xi_{g}(\cdot)\right\}}{\min }\left\{\varepsilon \int_{0}^{\theta^{*}} \xi_{g}(\theta) d F(\theta)\right\}
$$

s.t.

$$
\int_{0}^{\theta^{*}}\left[1-\xi_{g}(\theta)\right] \widetilde{\pi}(\theta) d F(\theta) \geq 0 \quad(\mu)
$$

The Lagrangian of this optimization problem is $-\varepsilon-\mu \widetilde{\pi}(\theta)$. Because $\tilde{\pi}(\theta)$ is strictly increasing (from Lemma 4), there is indeed a cutoff $\theta_{g}$ such that $\xi_{g}(\theta)=1$ if and only if $\theta<\theta_{g}$. Finally, the theorem of the maximum guarantees that as $\varepsilon$ converges to 0 , the optimum converges to the mechanism of subsection $B$. 